\title{
Modified approach for identifying weak zones for effective sand management
}

\author{
Aliyu Adebayo Sulaimon ${ }^{1}\left[\right.$ D $\cdot$ Lim Lee Teng ${ }^{1}$
}

Received: 23 July 2019 / Accepted: 19 September 2019 / Published online: 4 October 2019

(c) The Author(s) 2019

\begin{abstract}
Sand production is a major problem that the oil and gas industry has been facing for years. It can lead to loss of production, equipment damage or complete well abandonment. Prediction of sand has been historically challenging due to the periodic nature of sand production, insufficient laboratory tests and lack of field tests validation. Analyses have been performed to identify weak zones for planned wells, and common technique is the application of shear modulus and mechanical properties $\log$ (MPL) criteria developed by Tixier et al. (J Pet Technol 27:283-293, 1975). However, the set criteria have been found to be generally inadequate to detect transition zone or predict weak formation in some fields. In this study, using the knowledge of rock behavior, geomechanical properties and well log data, we have established new simple criteria for identifying fragile sections within a transition zone. In situ logging data from a field $X$, located in Sabah, Malaysia, and Field $Y$, located in Shimokita, Japan, were used in this study. Using the threshold for shear modulus and MPL, the criteria for the geomechanical properties are set to differentiate formation strengths at different depths. The threshold for Poisson's ratio is 0.34 , Young's modulus at $1.6 \times 10^{6} \mathrm{psi}$ and the unconfined compressive strength at $2400 \mathrm{psi}$. The MPL and geomechanical models were generated to predict sanding incident. The results were subsequently validated with artificial neural network using MATLAB. Also, critical wellbore pressure is calculated and acts as a guide to operate outside the sand failure envelope. Thus, the prediction of the weak formation using geomechanical properties has been further established in this study.
\end{abstract}

Keywords Weak sand $\cdot$ Mechanical properties $\log \cdot$ Geomechanical properties $\cdot$ Logging data $\cdot$ MATLAB

\section{Introduction}

Sand production during oil and gas production has been a major flow assurance issue for many decades. Oil production at high rates beyond the allowable may trigger failure, especially in unconsolidated formations. (Tixier et al. 1975; Aborisade 2011; Wang 2017). Material degradation within the completion environment is a major factor which may be caused by drilling operations, sudden and/or excessive pressure drop, frequent shutdown and startup, operating conditions and strength weakening effect of water (Rahmati et al. 2013). Formation failure could lead to excessive sand production which may adversely affect downhole completions, plug perforations, erode and damage subsurface and surface equipment as well as cause serious environmental hazards.

Aliyu Adebayo Sulaimon

aliyu.adebayor@utp.edu.my

1 Petroleum Engineering Department, Universiti Teknologi PETRONAS, Bandar Seri Iskandar, Malaysia
Many studies (Tixier et al. 1975; Palmer et al. 2003; Acock et al. 2004; Guinot et al. 2009; Osisanya 2010; Al-Awad 2012; Rahmati et al. 2013; Oyeneyin 2015; Balarabe and Isehunwa 2017; Subbiah et al. 2014; Willson et al. 2002; Deng et al. 2013; and Zhou and Sun 2016) have been conducted on sanding prediction, and yet no technique has been generally adopted by the stakeholders in the oil industry as the most accurate and reliable approach. Predictive models usually depend on formation and fluid properties that are often expensive and time-consuming to obtain from core samples (Yale and Jamieson 1994). Therefore, several correlations have been developed to relate variables such as production rate, pressure drop and rock and fluid properties. Nevertheless, the correlations are very approximate and can only serve as guides (Rahmati et al. 2013).

Mohamad-Hussein and Ni (2018) formulated a damage model using the Mohr-Coulomb failure criterion to describe the failure of porous granular material. They also conducted numerical analysis of a perforated well to evaluate the 
critical drawdown pressure for different reservoir properties. They concluded that the produced sand volume and sand mass rate increase with the drawdown pressure. Kolawole, Federer-Kovács and Szabó (2018) utilized a proprietary software to predict and quantify wellbore instability and sanding potentials in a Hungarian field. They were able to demarcate the formation into two separate intervals describing one zone as over-pressured, unconsolidated and highly stressed formation with a high tendency for wellbore failure during drilling process and with $90 \%$ possibility of wellbore instability. The other interval was described as the weakest, unconsolidated formation with high-risk sand production potential during well completion operation with a $70 \%$ potential of producing sand into the wellbore at this zone. However, they relied on a single-well analysis and were unable to validate their results with field data.

Ispas et al. (2002) compared the prediction of sanding and casing deformation for a well in the Gulf of Mexico (GoM) by deploying a British Petroleum (BP) onset of sanding model to calculate the critical bottom-hole flowing pressure (CBHFP) below which sand production would occur. Analyses showed that the model was able to predict sanding within $20 \%$ accuracy of the result from the postsanding observation. Ranjith et al. (2013) developed a sand production cell to investigate the impact of screen slot size, injection pressure and moisture content on sand production rate. They showed that sand production could occur more frequently through small openings from dry sand formations than from wet formations. The sand production rate increases with injection pressure but decreases with increasing moisture content. The authors also developed a sand production model which is not generally applicable but for a specific sand particle size. Akinsete et al. (2017) developed an analytical model for predicting sand production in gas and gas condensate wells. Utilizing the concept of erosional failure mechanism, they developed a model which indicated that sanding in weakly consolidated gas reservoirs is influenced by flow rate, fluid density and viscosity, density of sand, particle size and borehole radius.

The rock mechanical properties are not directly obtained from logging tools but can be derived from well log data or obtained from laboratory test (Ameen et al. 2009). The properties determined from well log data are called dynamic properties while those obtained from stress-strain laboratory measurements are referred to as static constant (Howarth 1984). In situ log measurements represent continuous profile of the formation strength (Hsieh et al. 2007). Sonic and density $\log$ s that are used to compute formation elastic constants serve as important indicators in sand prediction, and the combination of $\log$ data and mechanical properties shows good correlations (Fulong et al. 2013). Although laboratory tests provide reliable rock mechanics parameters, the experiments are time-consuming and complex (Karacan
2009). Rock mechanics tests require volumes of core samples with well-equipped testing facilities to obtain formation strength quantitatively. Studies show that the calculation of shear waves or compressional waves from well logs can be accurate and reliable (Tan et al. 2015).

Sanding problems can be minimized by reducing production rate to a level at which the formation can withstand the stresses in place. Restriction of flow rate would lead to decrease in cumulative production and loss of revenue; thus, reduction in production rate is not a financially attractive option. Hence, other practices such as sanding prediction should be considered for better sand management plan. For many years, several research works have been carried out on sanding prediction. Mechanical properties log (MPL) is famous for sanding prediction. This method uses well log data to analyze formation mechanical properties (Tixier et al. 1975; Eyinla and Oladunjoye 2014). However, the technique when exclusively applied is inadequate to identify the transition zones in the formation as explained later. It should therefore be integrated with other techniques for proper and adequate diagnosis.

In this study, based on the concept of dynamic elastic constants and other geomechanical properties, we have developed new criteria for evaluating sanding potential and weak zone identification. The formation properties are used to obtain critical wellbore pressure for calculating maximum drawdown of the well. The study focuses on the qualitative identification of sanding potentials in clean sands using the geomechanical properties and well log data to develop new criteria for reliable identification of fragile zones that are susceptible to sand failure. Prediction of critical production rate, sand accumulation in wellbore and screen selection are not considered. Well logs and other well data from a Field $X$ located in Sabah, Malaysia, and Field $Y$ which is situated in Shimokita, Japan, were used for case study.

\section{Description of Field $X$ and Field $Y$}

\section{Field $X$}

Field $X$ is located in Block SB-XX, Offshore Sabah, Malaysia (Fig. 1). The area consists of a series of oil and gas fields discovered in Late Miocene Stage IVc sediments. Petrophysics at rig indicate the main lithofacies are mainly sandstones and shales. The geological features consist of mainly anticline and syncline structure which indicates high possibilities of fault presence between the reservoir units. Two exploration wells have been drilled, and measurement-whiledrilling (MWD) procedure was used to obtain information such as true vertical depth (TVD), directional angle, as well as north-south (NS) and east-west (EW) departure. So far, there has been no study to predict sanding in Field $X$. Therefore, this study is conducted to characterize the formation 


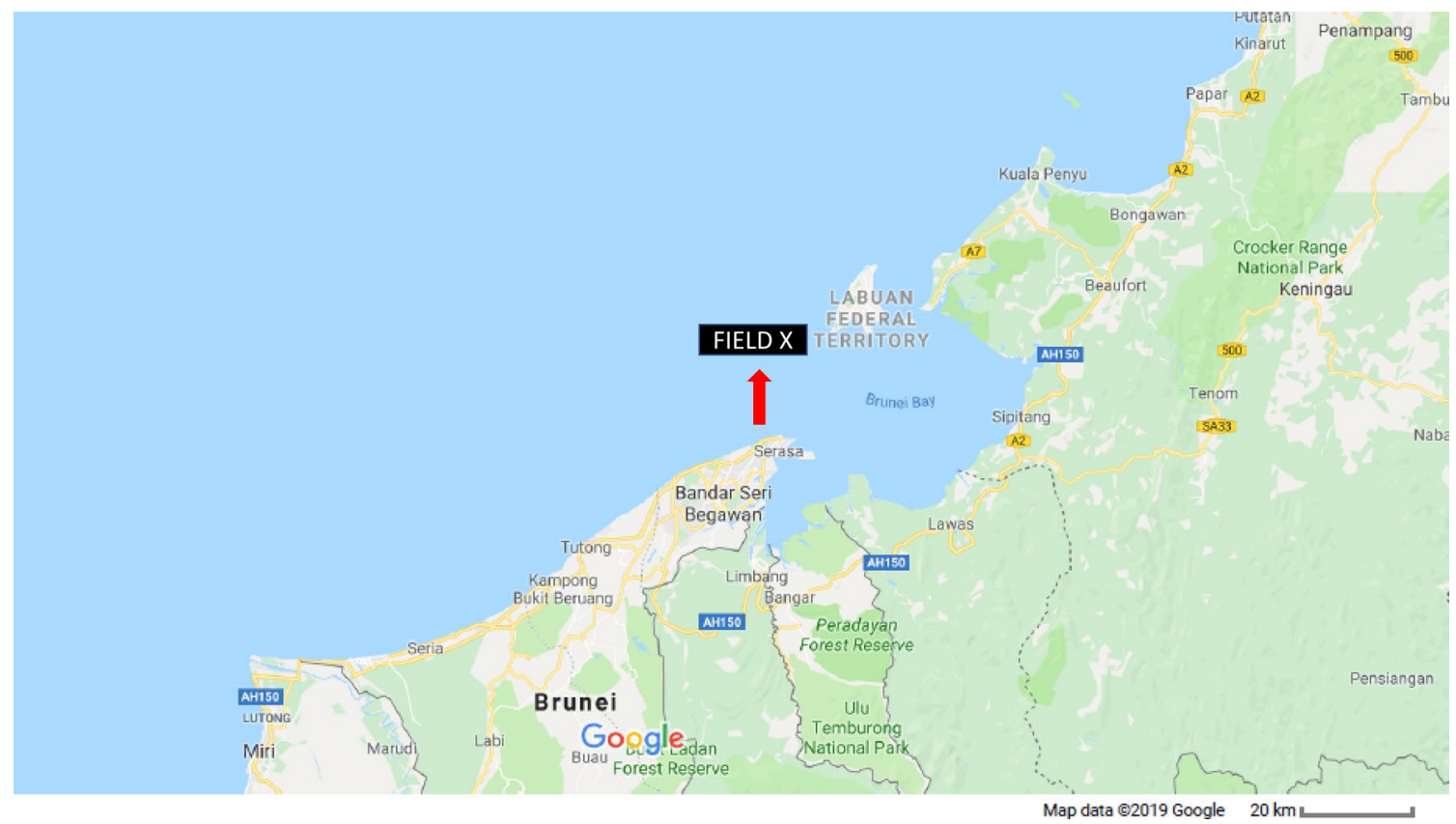

Fig. 1 Map showing the location of Field $X$

mechanical properties to evaluate the necessity for sand control. Density and sonic log data were used to determine the geomechanical properties of the formation. The source rock of West Sabah Basin is rich in terrigenous organic matter in sedimentary intervals, and the thickness is approximately $220 \mathrm{~m}$ within the measured depths of $1330 \mathrm{~m}$ and $1550 \mathrm{~m}$. The interval is characterized by soft-to-friable, blocky claystone with very fine quartz grain and moderately hard-towell-sorted sandstone with fair intergranular porosity.

During the drilling of the $12-1 / 4$-inch hole, the rate of penetration (ROP) decreased from $15 \mathrm{~m} / \mathrm{h}$ within the interval $1201-1402 \mathrm{~m}$ to $6.5 \mathrm{~m} / \mathrm{h}$ through the interval $1402-1487 \mathrm{~m}$. The types of HTC drill bit used for the two intervals were MX-C03 and MX-09DX, respectively. The change in the ROP indicates the stratigraphic transition from weak to stronger zone. Stratigraphic analysis showed the interbedding of claystone and thin sandstone within the zone $1120 \mathrm{~m}$ to $1320 \mathrm{~m}$ and interbedding of sandstone and claystone in the interval $1320 \mathrm{~m}$ to $1636 \mathrm{~m}$. Analyses showed that the formation at the depth of $1558 \mathrm{~m}$ situates $60 \%$ of sandstone characterized as light gray, olive gray, clear, transparent to translucent, soft to friable, dominantly very fine quartz grains, poorly consolidated, silty in part, sub-rounded to rounded, moderate to well sorted, trace carbonaceous materials and microlaminae, interbedded with brownish gray claystone (40\%), trace mica, trace argillaceous matrix, noncalcareous to slightly calcareous, poor-to-fair intergranular porosity and poor shows. These descriptions indicate a weak formation. Below this zone, at a depth of $1573.1 \mathrm{~m}$, the sandstone is also characterized as light gray, olive gray, clear, transparent to translucent, soft to friable, dominantly very fine quartz grains, poorly consolidated, silty in part, sub-rounded to rounded, but moderate to well sorted, trace carbonaceous materials, trace mica, trace argillaceous matrix, noncalcareous, fair intergranular porosity and fair shows; this indicates a stronger interval than the overlying layers.

Production tests were conducted in a 9-5/8-inch cased hole section. The oil well produced $24^{\circ}$ API crude oil at the rates of $1378 \mathrm{STB} / \mathrm{D}$ and $0.16 \mathrm{MMSCF} / \mathrm{D}$ with an average gas-oil ratio (GOR) of 119 SCF/STB with 32/64" hoke size. The well was later produced at the maximum rates of 2745 STB/D with $0.73 \mathrm{MMSCF} / \mathrm{D}$ and the GOR of $267 \mathrm{SCF} / \mathrm{STB}$ with the choke size of 128/64". There were no water and sand productions during the maximum flow period.

\section{Field $Y$}

Field $Y$ is located offshore Shimokita Peninsula (Japan Sea) with water depth of $1180 \mathrm{~m}$ as illustrated in Fig. 2. Stratigraphic analysis shows that the oldest sediment recovered is of Oligocene to early Miocene geologic epoch. Lithology of Site $C-X$ is made up of mainly sandstone, shale, siltstone and coal (Fig. 3). The formation consists of deeply buried sediments, and riser drilling technology was employed to drill in two phases: from 647 (mud depth below seafloor) to 1257 mbsf and from 1257 to 2466 mbsf. With favorable borehole condition, good-quality log data were obtained, and 32 sediment cores were retrieved. 
Fig. 2 Map showing the location of Field $Y$

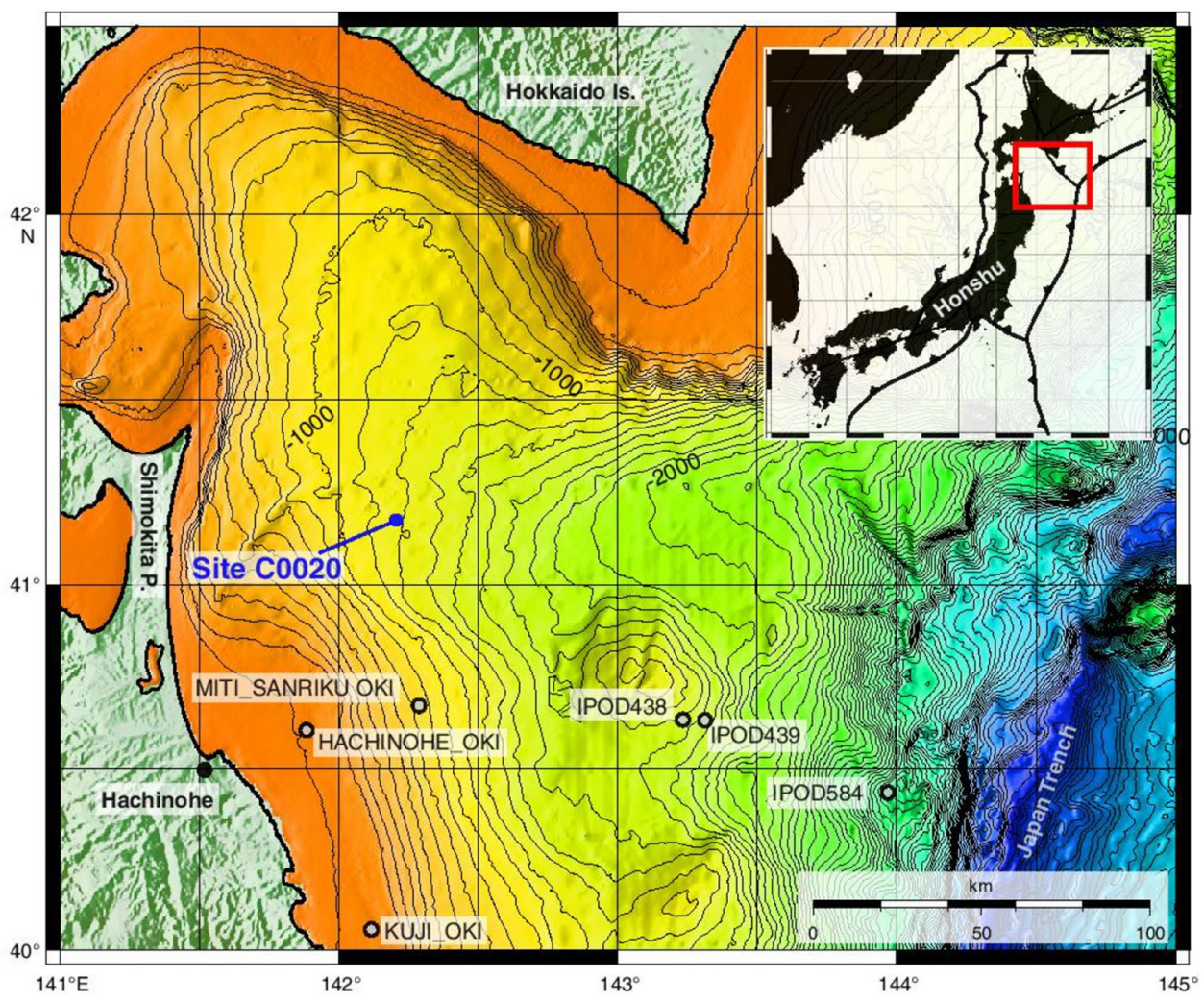

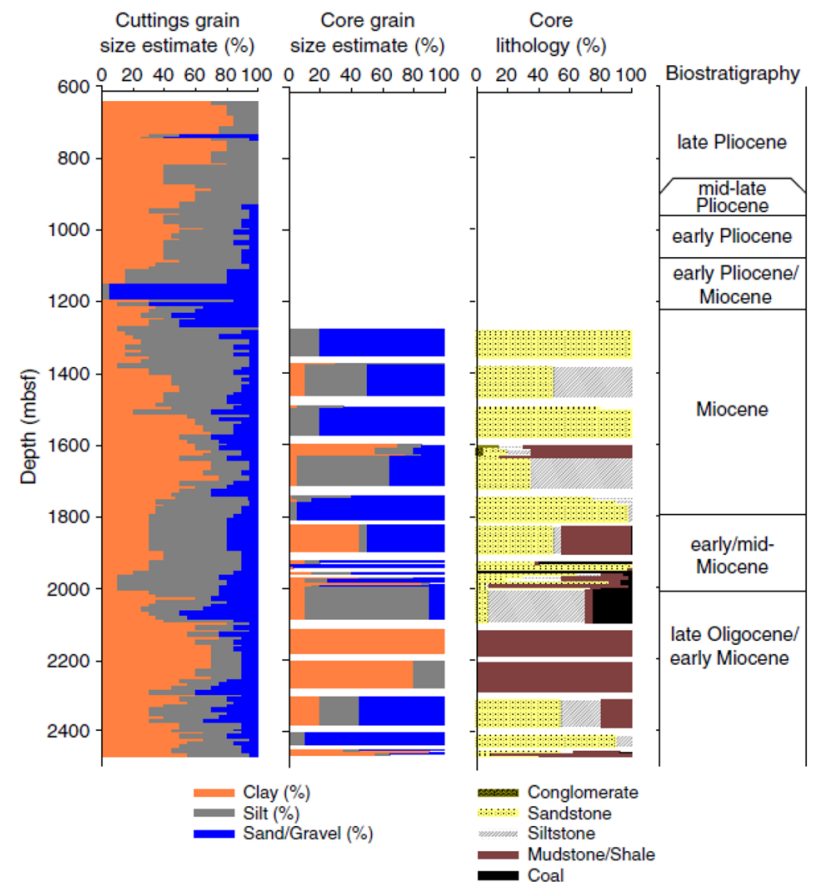

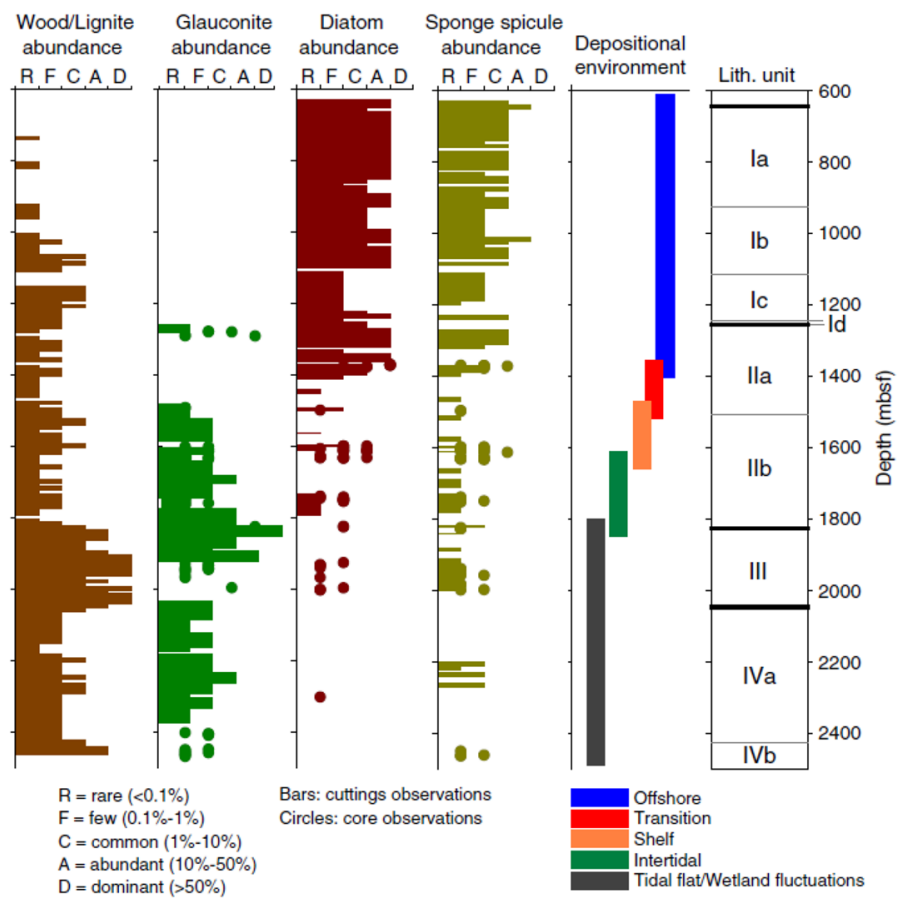

Fig. 3 Lithostratigraphic units of Field Y. source Inagaki F, Hinrichs KU, Kubo Y. (2013). Expedition 337 summary, Expedition 337 Scientists, Proc. IODP | Volume 337. https://doi.org/10.2204/iodp.proc.337.101.2013 


\section{Methodology}

In this study, the elastic constants and Mohr-Coulomb concept were used to generate a geomechanical model. Sonic and density well log data are the main input used in this work. The in situ log measurements are fairly representative of the downhole formation architecture, and modeling of sand production by using formation rock properties is reliable as the quality of the data (Yale and Jamieson 1994; Dong et al. 2013; Cui et al. 2017). The mechanical properties log (MPL) is applied in this study to distinguish between weak and strong sands by using the concept of dynamic elastic constants (Khamehchi and Reisi 2015; Osisanya 2010). According to Hsieh et al. (2009), the major parameters that affect formation strength include bulk compressibility $\left(C_{\mathrm{B}}\right)$, shear modulus $(G)$, uniaxial or unconfined compressive strength (UCS) and Young's modulus, $(E)$. Compressional velocity, shear velocity and bulk density are obtained from sonic and density logs. Using stress-strain relationships, mechanical properties of the rock can be determined.

The shear modulus, bulk modulus and bulk compressibility are used to generate the MPL. The calculated MPL is then used along with the elastic constants and uniaxial or unconfined compressive strength (UCS) to determine the critical wellbore pressure as illustrated in Figs. 4, 5 and 6. Using the compressional and shear wave transit time as input parameters, the artificial neural network (ANN) in MATLAB software is subsequently used to establish strong correlation.

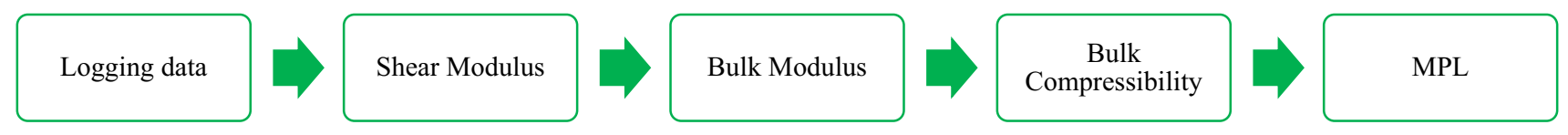

Fig. 4 Flowchart of MPL

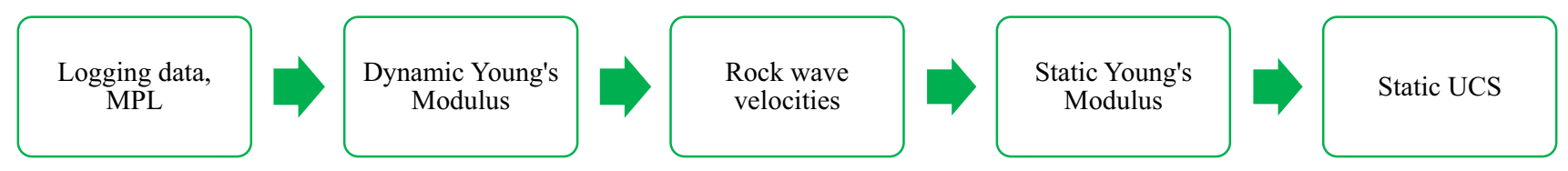

Fig. 5 Flowchart of geomechanical model

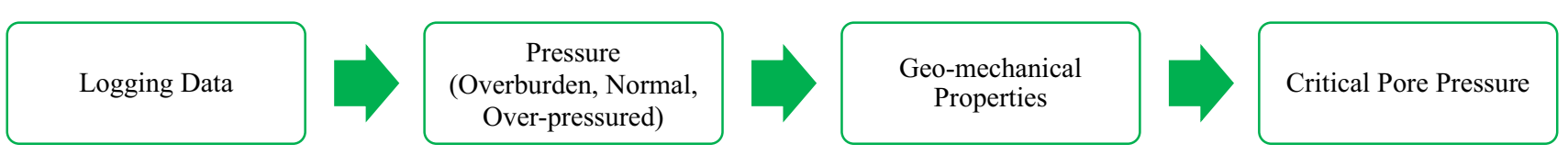

Fig. 6 Flowchart for calculating the critical pore pressure [Mohr-Coulomb's Criterion]

Relying on well log data, the mechanical properties log (MPL) is one of the popular methods that are used to evaluate sand failure. However, there are some limitations associated with this method. The inability to identify 'transition zone' makes it susceptible to erroneous interpretation of the formation strength which could ultimately lead to confusion and wrong decision in the prevention and proper management of sand failure. We define transition zone as a region characterized by gradual change in formation strength between an unconsolidated or weak layer(s) and compacted or hard zone(s). The MPL was applied in this study to distinguish between weak and strong sands using computation of elastic modulus (Khamehchi and Reisi 2015; Osisanya 2010).

Major parameters that affect formation strength include bulk compressibility $\left(C_{\mathrm{B}}\right)$, shear modulus $(G)$, unconfined compressive strength (UCS) and Young's modulus (Hsieh et al. 2009). Tixier et al. (1975) computed a critical value of $0.8 \times 10^{12} \mathrm{psi}^{2}$ for the MPL and $0.6 \times 10^{6} \mathrm{psi}$ for the shear modulus with values greater than the set thresholds indicating no sanding problem. The MPL $\left(\mathrm{psi}^{2}\right)$ criterion is defined as a function of the shear modulus (G, psi) and bulk compressibility, $C_{B}$ in $\mathrm{psi}^{-1}$ (Tixier et al. 1975; Kowalski 1975; Sethi 1981, Gatens et al. 1990):

$\mathrm{MPL}=\frac{G}{C_{\mathrm{B}}}$

where

$G=\frac{\rho}{\Delta t_{\mathrm{s}}^{2}} \times 1.34 \times 10^{10}$ 
and

$C_{B}=\frac{1}{K_{B}}$

where $\Delta t_{\mathrm{s}}$ is the shear wave specific acoustic time ( $\left.\mu \mathrm{sec} / \mathrm{ft}\right)$ and the bulk modulus $\left(K_{\mathrm{B}}, \mathrm{psi}\right)$ is given as

$K_{\mathrm{B}}=\rho\left(\frac{3 \Delta t_{\mathrm{s}}^{2}-4 \Delta t_{\mathrm{c}}^{2}}{3 \Delta t_{\mathrm{s}}^{2} \Delta t_{\mathrm{c}}^{2}}\right) \times 1.34 \times 10^{10}$

where $\rho$ is the bulk density ( $\mathrm{g} / \mathrm{cc})$ and $\Delta t_{\mathrm{c}}$ is the compressional wave specific acoustic time $(\mu \mathrm{sec} / \mathrm{ft})$. According to Tixier et al. (1975), the maximum sand-free rate can be established when $G / C_{b}$ is within $\pm 10 \%$ of the accepted threshold of $0.8 \times 10^{12} \mathrm{psi}^{2}$.

\section{Application of MPL and shear modulus criteria to Field $X$}

Tixier et al. (1975) recommended the critical value of $0.8 \times 10^{12} \mathrm{psi}^{2}$ for the MPL and $0.6 \times 10^{6} \mathrm{psi}$ for the shear modulus with values greater than the set thresholds indicating no sanding problem. In other words, when $G>0.60 \times 10^{6} \mathrm{psi}$ and $C_{\mathrm{B}}<0.75 \times 10^{-6} \mathrm{sq}$ in./lb (i.e., MPL $>0.8 \times 10^{12} \mathrm{psi}^{2}$ ), the formation is strong or compacted; otherwise, the sand is considered weak, fragile or uncompacted. However, there are limitations in the application of MPL criterion due to occasional ambiguity in the identification of the transition zones.
The MPL and shear modulus are determined from well log data, and Figs. 7 and 8 illustrate the plots of MPL and shear modulus with depth, respectively. From Fig. 7, the Tixier et al.'s (1975) criterion fails to identify the region between 1120 and $1500 \mathrm{~m}$. In this study, this region is defined as the transition zone between the weak and strong formations. To the best of our knowledge, the MPL has not been used to differentiate between the soft and hard sections within the transition zone. Furthermore, the MPL sometimes gives conflicting results as shown in Figs. 7 and 8. According to the MPL criterion, Fig. 7 shows that below $1500 \mathrm{~m}$, the formation is strong or hard. However, the shear modulus threshold of $0.6 \times 10^{6} \mathrm{psi}$ in Fig. 8 shows that the more consolidated zone can be found above $1320 \mathrm{~m}$. This inconsistency calls for further investigation to develop a new or additional criterion to resolve the observed conflict between the MPL and the shear modulus criteria for qualitative estimation of formation strength. An important peculiar attribute of the transition zone is that it is characterized by a line of a relatively infinite slope or vertical gradient as shown in Fig. 7. This observation has been employed in the development of a new threshold for the MPL.

\section{Geomechanical model}

The knowledge of rock mechanical properties and behaviors is important for effective well management and accurate sand prediction analysis (Wang et al. 2004). Well log data and MPL results are used to determine the geomechanical properties. The main output from the model includes Poisson's ratio ( $v)$, Young's modulus $(E)$ and unconfined compressive stress (UCS). Several mathematical relations have

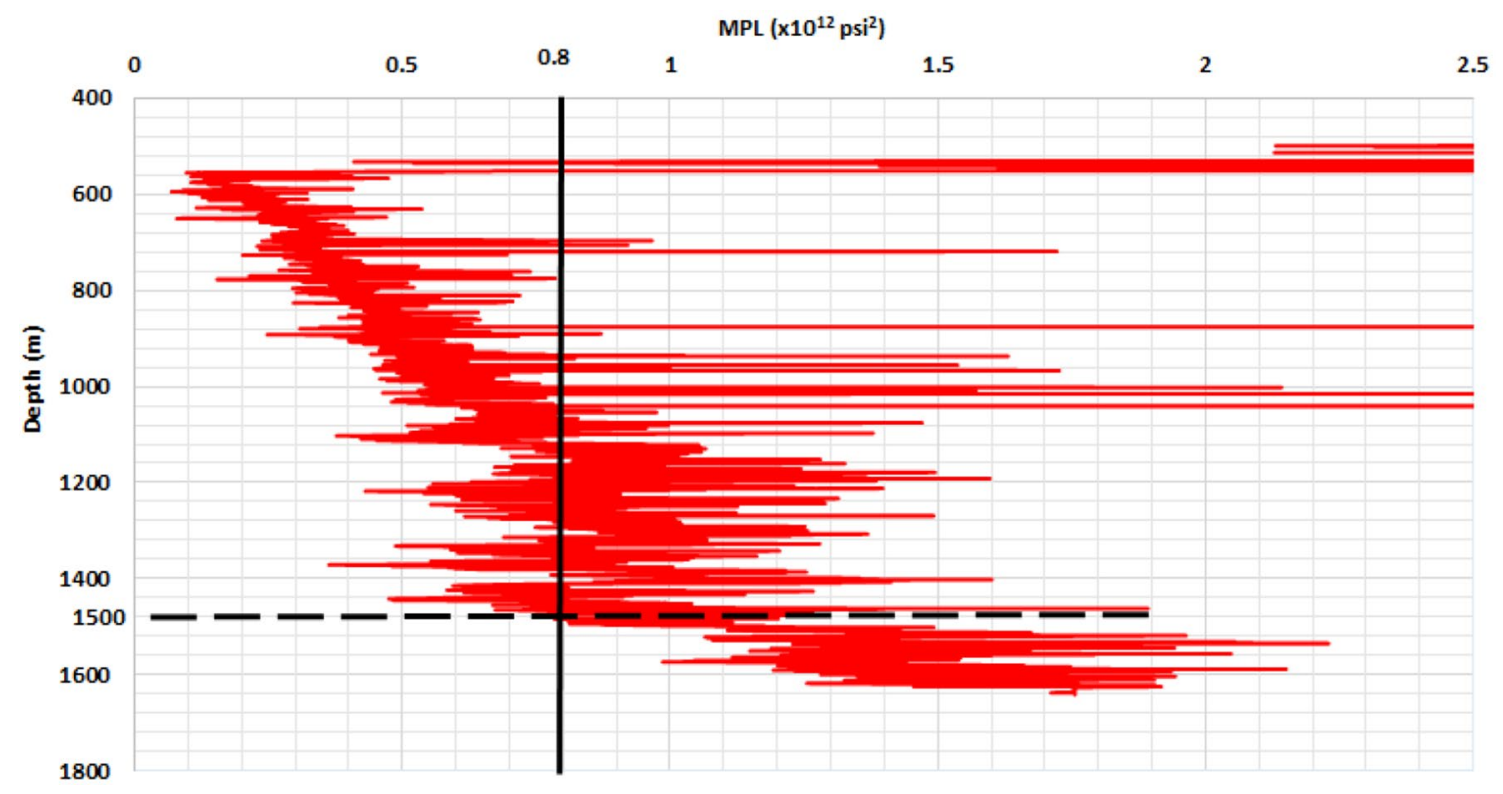

Fig. 7 MPL with depth 


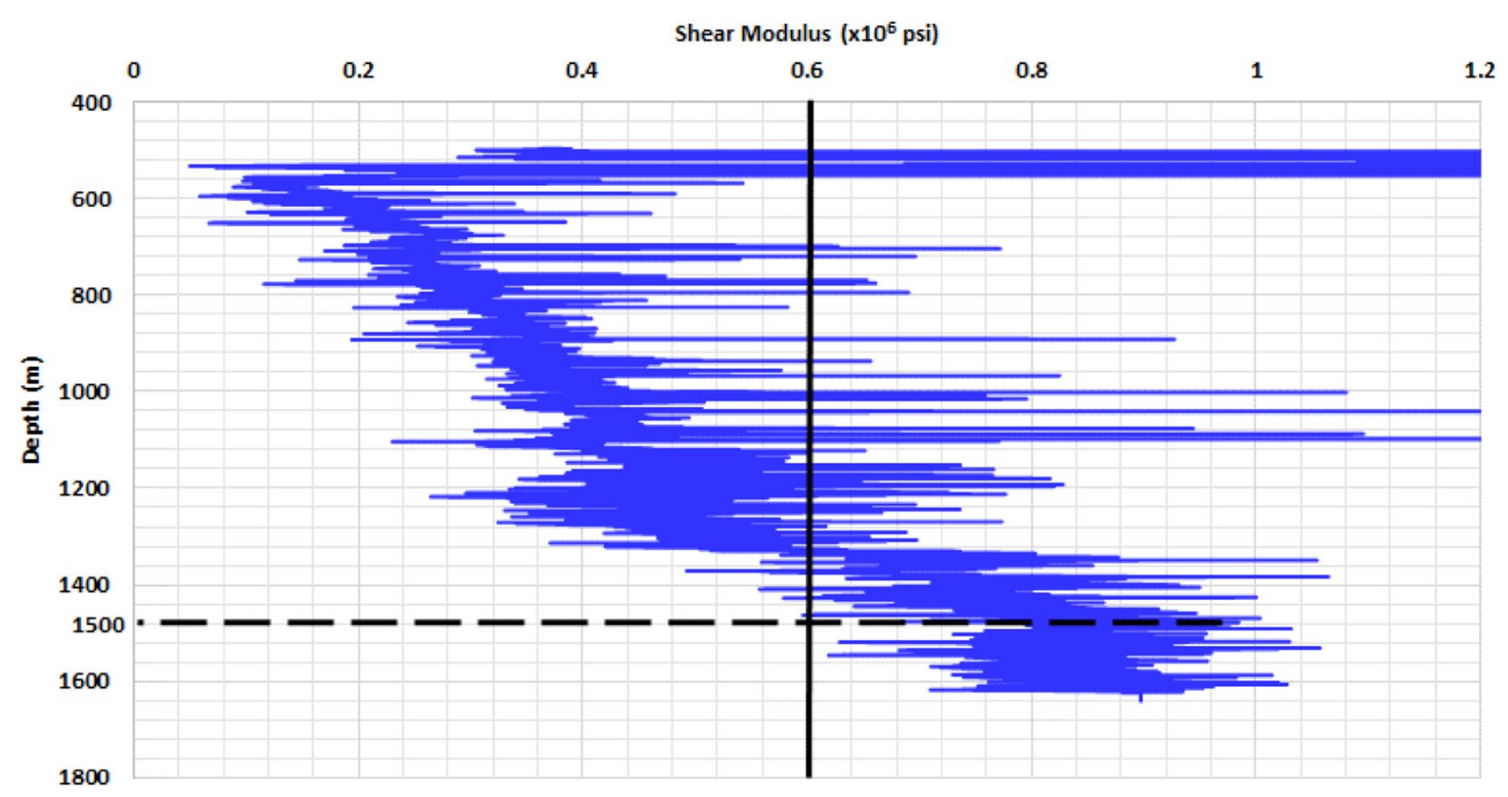

Fig. 8 Shear modulus with depth

been developed to estimate the elastic constants and other geomechanical properties (Bradford et al. 1998; Rajabi et al. 2010; Horsrud 2001; Zhaoping et al. 2002). Nevertheless, all the correlations rely on well log data.

The rock mechanical properties are not directly obtained from logging tools but can be derived from well log data or obtained from laboratory test (Ameen et al. 2009). The properties determined from well log data are called dynamic properties while those obtained from stress-strain laboratory measurements are referred to as static constant (Howarth 1984). In situ log measurements represent continuous profile of the formation strength (Hsieh et al. 2007). Sonic and density $\operatorname{logs}$ that are used to compute formation elastic constants serve as important indicators in sand prediction, and the combination of log data and mechanical properties shows good correlations (Fulong et al. 2013). Although laboratory tests provide reliable rock mechanics parameters, the experiments are time-consuming and complex (Karacan 2009). Rock mechanics tests require volumes of core samples with well-equipped testing facilities to obtain formation strength quantitatively. Studies show that the calculation of shear waves or compressional waves from well logs can be accurate and reliable (Tan et al. 2015).

It is important to know the rock properties and mechanical behaviors for accurate sand prediction analysis. The compressional or $P$ wave $\left(V_{\mathrm{p}}\right)$ and shear or $S$ wave $\left(V_{\mathrm{s}}\right)$ velocities are the fundamental parameters for geomechanical studies. The data can be directly obtained from dipole sonic imager tools while well logs can provide continuous input data for entire well (Rajabi et al. 2010; Bradford et al. 1998; Horsrud 2001). The dynamic elastic modulus and Poisson's ratio can be calculated from log data such as bulk density, shear and compressional transit times $\left(\Delta t_{\mathrm{s}} \& \Delta t_{\mathrm{c}}\right)$ as shown in Eqs. (5) and (6) (Onyia 1988; Zhaoping et al. 2002; Khair et al. 2015):

$E_{\text {dynamic }}=\frac{\rho}{\Delta t_{\mathrm{c}}^{2}}\left(\frac{3 \Delta t_{\mathrm{s}}^{2}-4 \Delta t_{\mathrm{c}}^{2}}{\Delta t_{\mathrm{s}-}^{2} \Delta t_{\mathrm{c}}^{2}}\right) \times 1.34 \times 10^{10}$

$v=\frac{1}{2} \frac{\Delta t_{\mathrm{s}}^{2}-2 \Delta t_{\mathrm{c}}^{2}}{\Delta t_{\mathrm{s}}^{2}-\Delta t_{\mathrm{c}}^{2}}$

The dynamic elastic modulus is used to determine the static Young's modulus by using the Lacy (1997) correlation as shown in Eq. (7) while the static UCS is calculated from Freyburg (1972) as shown in Eq. (8). Rock brittleness can be estimated from the Young's modulus and UCS; soft sands usually have low Young's modulus and UCS values:

$E_{\text {static }}=0.0293 E_{\text {dynamic }}^{2}+0.4533 E_{\text {dynamic }}$

$\mathrm{UCS}=0.035 V_{\mathrm{p}}-31.5$

where $v$ is the Poisson's ratio; $\Delta t_{\mathrm{c}}$, compressional wave transit time, $\mu \mathrm{s} / \mathrm{ft} ; \Delta t_{\mathrm{s}}$, shear wave transit time, $\mu \mathrm{s} / \mathrm{ft} ; E_{\text {static }}$, static elastic modulus, psi; $E_{\text {Dynamic }}$, dynamic Young's modulus, psi; UCS, unconfined compressive strength, psi; and $V_{\mathrm{p}}$, compressional $\mathrm{P}$ wave velocity, $\mathrm{ft} / \mathrm{s}$. 
The wave velocities are expressed by Eqs. 6 and 7 (Miller and Stewart 1991):

$V_{\mathrm{p}}=\sqrt{\frac{K_{\mathrm{B}}+\frac{4}{3} G}{\rho}}$

$V_{\mathrm{s}}=\sqrt{\frac{G}{\rho}}$

where $V_{\mathrm{p}}$ and $V_{\mathrm{s}}$ are $\mathrm{P}$ wave velocity ( $\mathrm{ft} / \mathrm{s}$ ) and $\mathrm{S}$ wave velocity $(\mathrm{ft} / \mathrm{s})$, respectively.

\section{Mohr-Coulomb calculation}

Once the geomechanical properties are determined, the next step is to generate the Mohr-Coulomb model. The output from this model is the critical wellbore pressure, which is used to determine the maximum wellbore pressure that a well can produce without sand failure (Hayavi and Abdideh 2016; Galindo et al. 2017; Al-Ajmi and Zimmerman 2007). Prediction of sand production using the Mohr-Coulomb model considers several parameters, including friction angle and rock cohesion, pressure, Poisson's ratio, UCS, as well as both the shear stress and normal stress that are functions of both the minimum stress and maximum principal stress (Osisanya 2010; Mirzaahamdian 2011; Al-Awad 2012; Labuz and Zang 2012). Figure 9 shows a sketch of the Mohr-Coulomb criterion of failure envelope. The critical wellbore pressure, $P_{\mathrm{c}}$, is given in Eq. (11):

$P_{\mathrm{c}}=\frac{1.5 \sigma_{x}-0.5 \sigma_{y}-0.5 \alpha P_{p}\left(\frac{1-2 v}{1-v}\right)-1.732 \tau_{i}}{1-0.5 \alpha\left(\frac{1-2 v}{1-v}\right)}$.

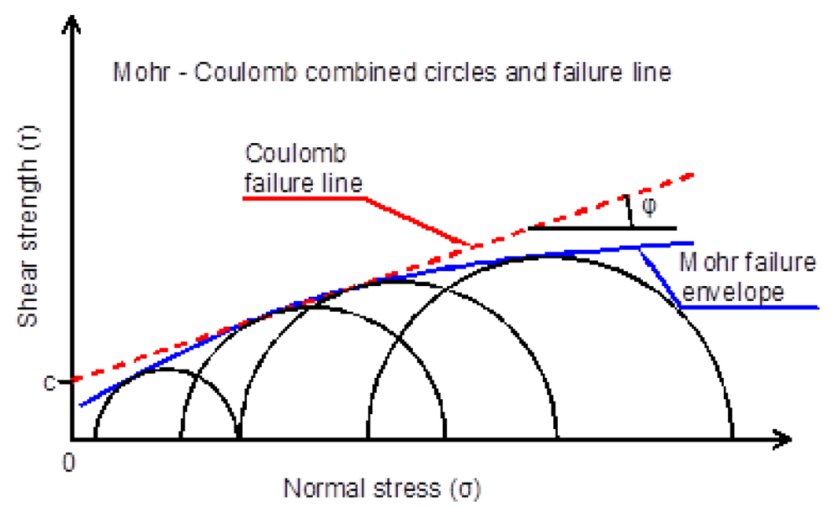

Fig. 9 Mohr-Coulomb criterion for failure. Source: Holtz and Kovacs (1981) where $\sigma_{x}$ is stress in $x$-direction, psi; $\sigma_{y}$, stress in $y$-direction, psi; $\alpha$, constant; $v$, Poisson's ratio; and $\tau_{\mathrm{i}}$, initial shear strength, psi.

\section{MATLAB validation}

When possible, log-derived dynamic rock properties should be calibrated to core-derived static properties. After computing the model parameters, MATLAB software was used to correlate the calculated geomechanical properties and the static properties for the weak zone prediction. The artificial neural network (ANN) was used to validate the calculations from both MPL and geomechanical models. ANN provides the most reliable prediction from well log data as empirical correlations can be obtained from ANN (Qi and Carr 2006; Khamehchi et al. 2014; Araujo Guerrero et al. 2014; Elkatatny et al. 2016). Time-series prediction was applied where compressional and shear wave transit times act as the input data for this prediction. In this study, $70 \%$ of the data were used for training, $15 \%$ were for validation and the remaining $15 \%$ were for result testing. Using MATLAB time-step prediction, both MPL and geomechanical models are validated.

\section{Results and discussions}

\section{Mechanical properties log}

In Field $X$, as shown in Fig. 10, shear modulus $(G)$ increases with depth. Shear modulus for Field $X$ is relatively low, with most of the formation less than $1 \times 10^{6} \mathrm{psi}$, and the average value of $\mathrm{G}$ is around $0.52 \times 10^{6} \mathrm{psi}$, which is lower than the threshold of $0.6 \times 10^{6}$ psi which was set by Tixier et al. (1975). This indicates the formation is relatively weak. The transition zone defined in this project is when the line of slope approaches infinity. As shown in Fig. 10, there is a transition zone between depths of $1120 \mathrm{~m}$ to $1500 \mathrm{~m}$.

As shown in Fig. 11, most of the formations of Field $X$ have small MPL reading with an average value of $1 \times 10^{12} \mathrm{psi}^{2}$. From the graph, we can see that the strength of formation increases with depth. Similar to the shear modulus graph, the transition zone is observed at depth from 1120 to $1500 \mathrm{~m}$. Starting from $1500 \mathrm{~m}$, the formation starts to fall within the acceptable range.

Figure 12 shows the correlation results of MPL with all having an $\mathrm{R}$ value of average 0.97 . A perfect alignment with the line will have an $R$ value of 1 . The training results using MATLAB show a positive outcome. Way forward to increase the accuracy of the training would be reducing the noise of MATLAB generated by sonic log.

In Field $Y$, as shown in Fig. 13, the shear modulus has an average value of $0.44 \times 10^{6} \mathrm{psi}$, comparatively lower than 




Fig. 10 Shear modulus of Field $X$

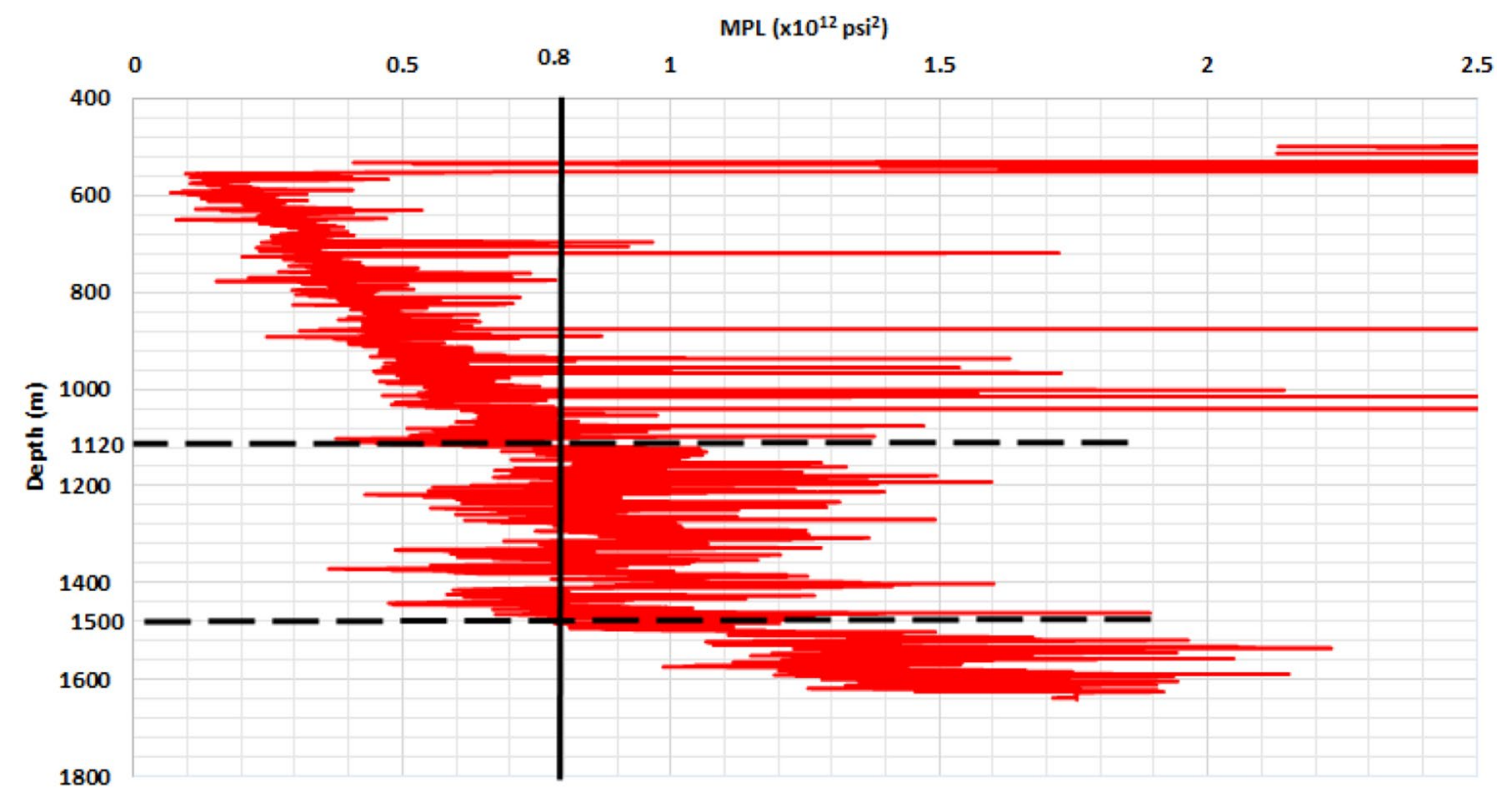

Fig. 11 MPL value of Field $X$

the threshold value. Two transition zones were observed at a depth between $1760 \mathrm{~m}$ to $2000 \mathrm{~m}$ and $2140 \mathrm{~m}$ to $2440 \mathrm{~m}$. The first transition zone seems to move toward the soft formation, as the majority of the values are less than the threshold. Alternatively, the second transition zone shows quite average formation strength. Between these two transition zones, there is a decreasing trend below the threshold. This shows the formation easily deformed when force or stress is applied.
Graph of MPL versus depth is shown in Fig. 14. Compared to the Tixier et al.'s (1975) criterion, shallower formation in Field $Y$ has relatively low MPL value with a minimum point of $0.26 \times 10^{12} \mathrm{psi}^{2}$; this indicates that shallower formations are softer than deeper intervals. Starting from $1760 \mathrm{~m}$, an infinite slope can be found up to a depth of $2000 \mathrm{~m}$. This also applies to a depth between 2140 and $2440 \mathrm{~m}$. The second transition zone shows a relatively harder 
Fig. 12 MATLAB model validation of Field $X$
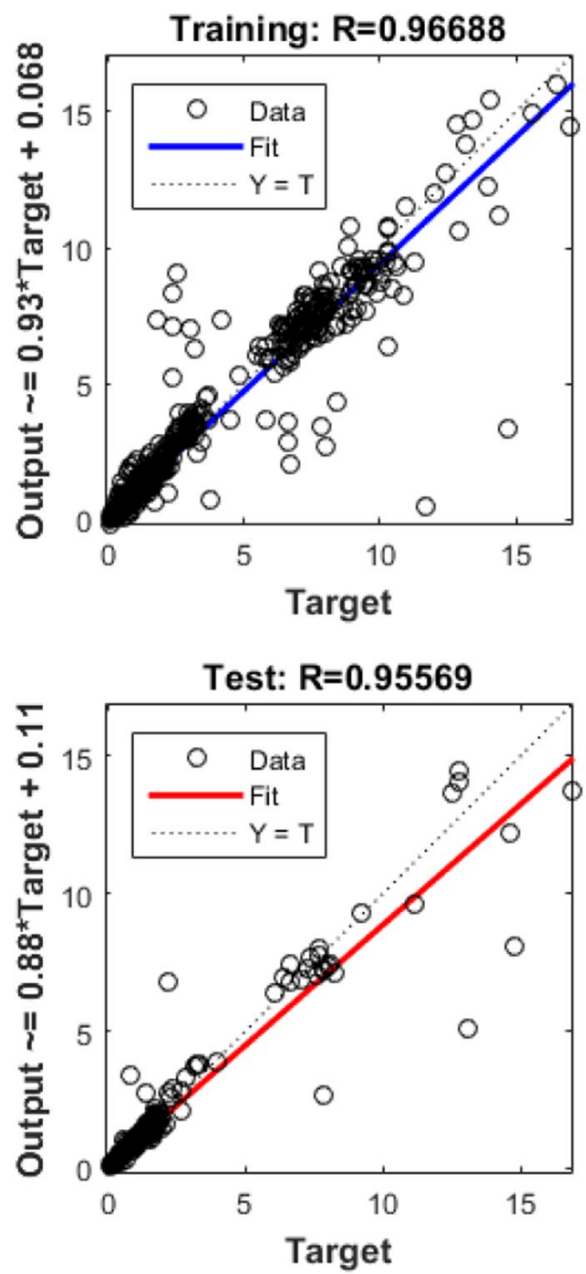
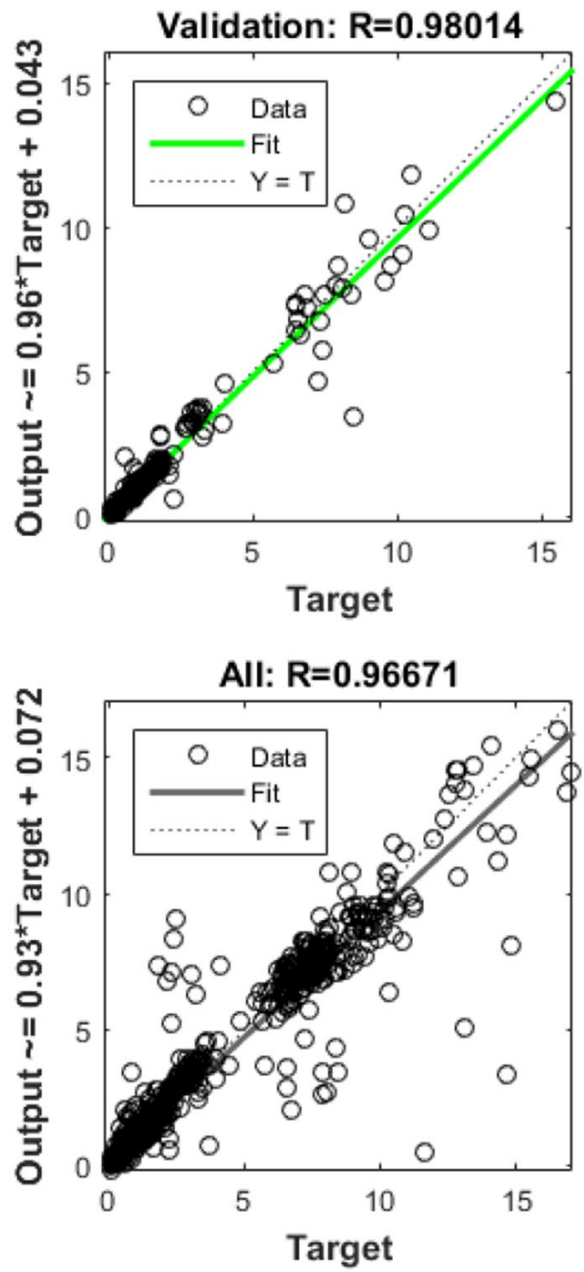

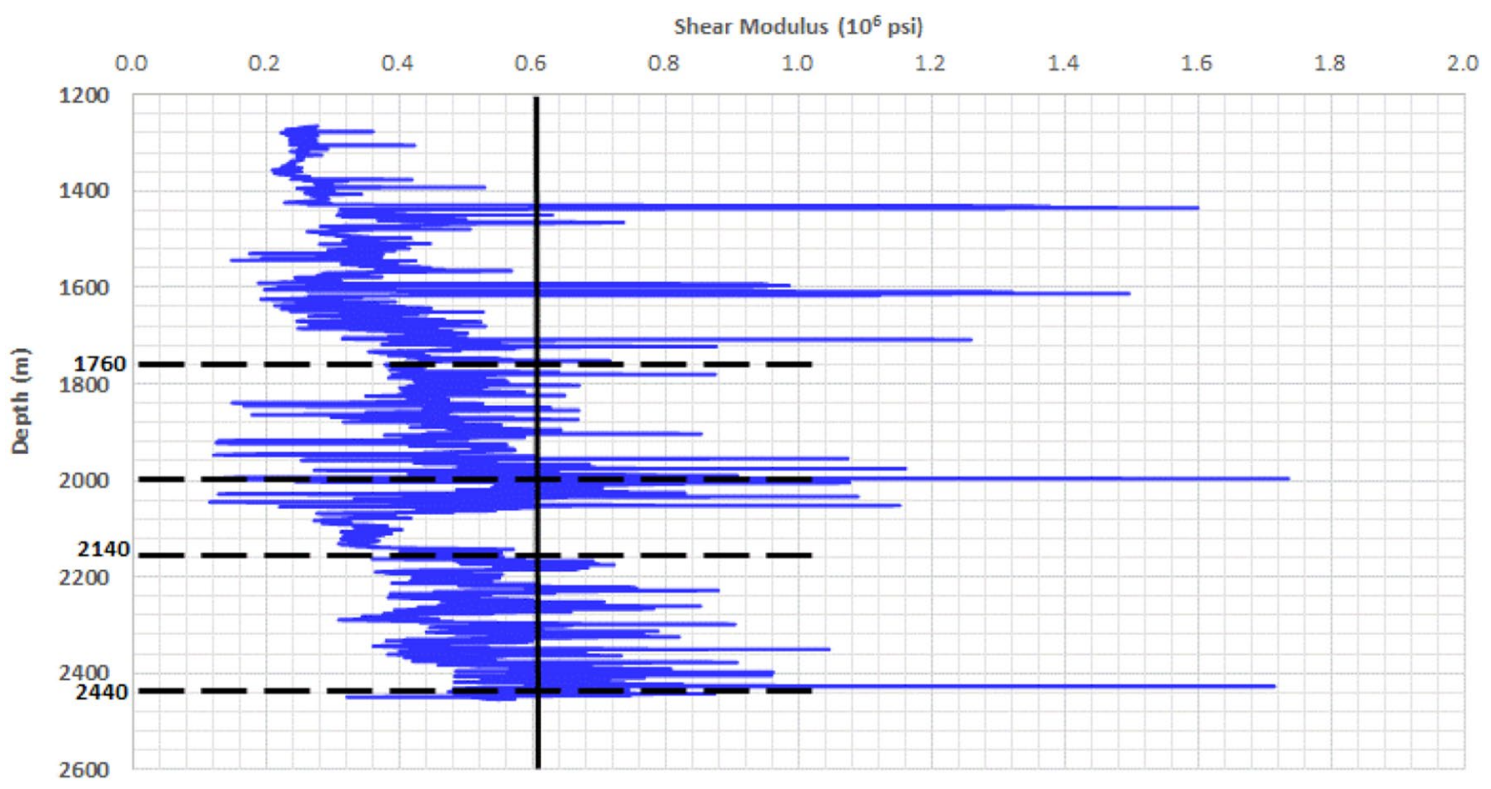

Fig. 13 Shear modulus of Field $Y$ 


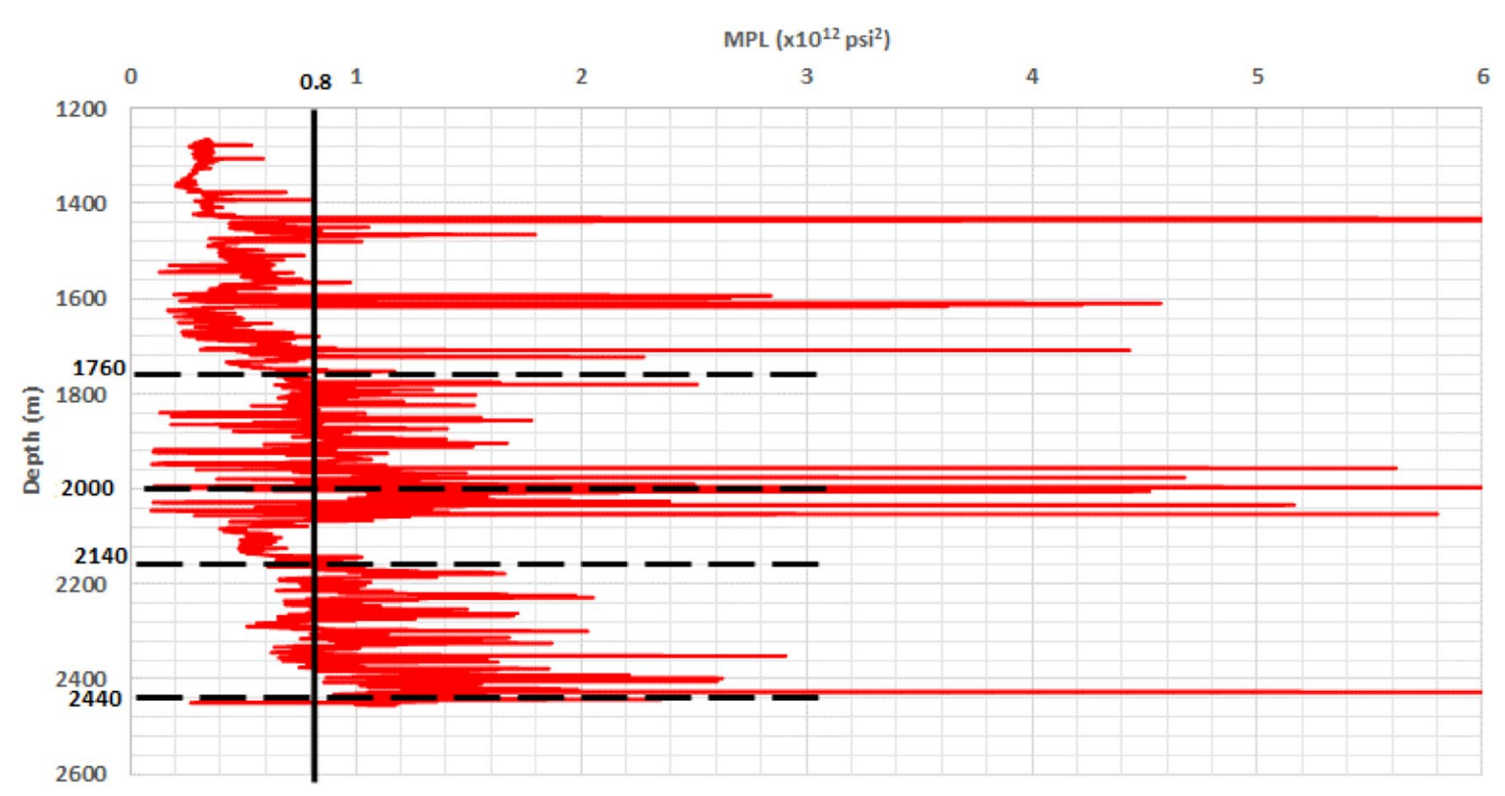

Fig. 14 MPL value of Field $Y$

Fig. 15 MPL model validation of Field $Y$
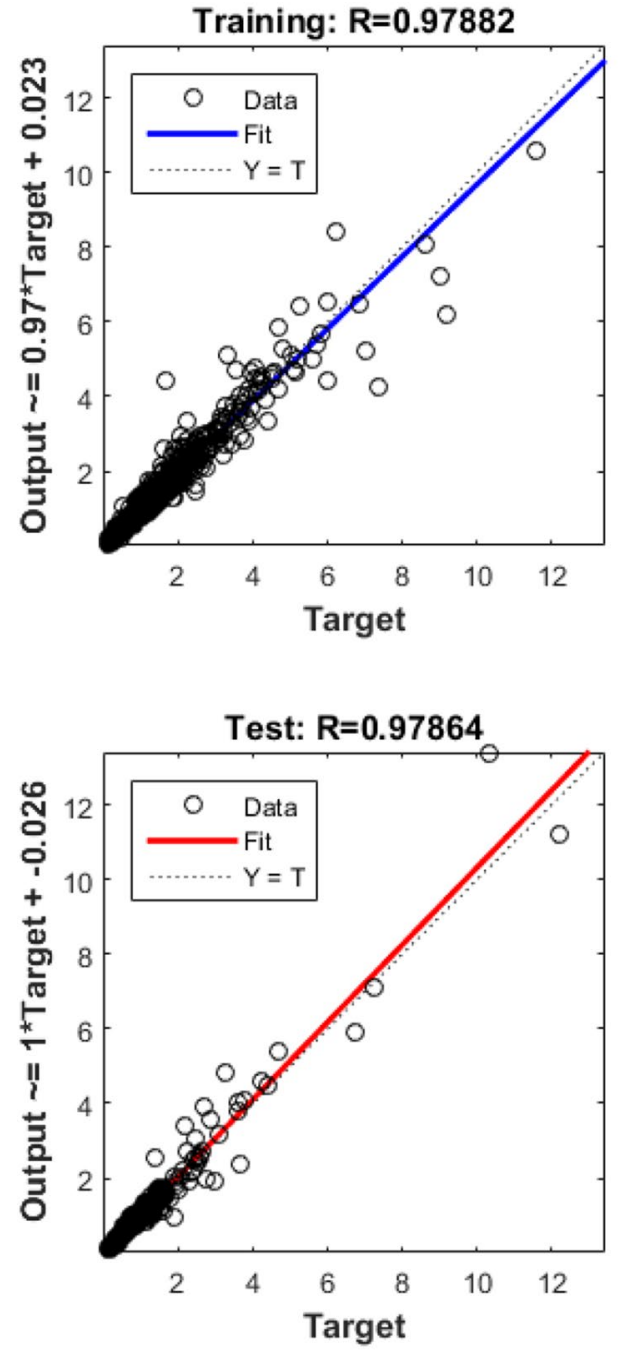
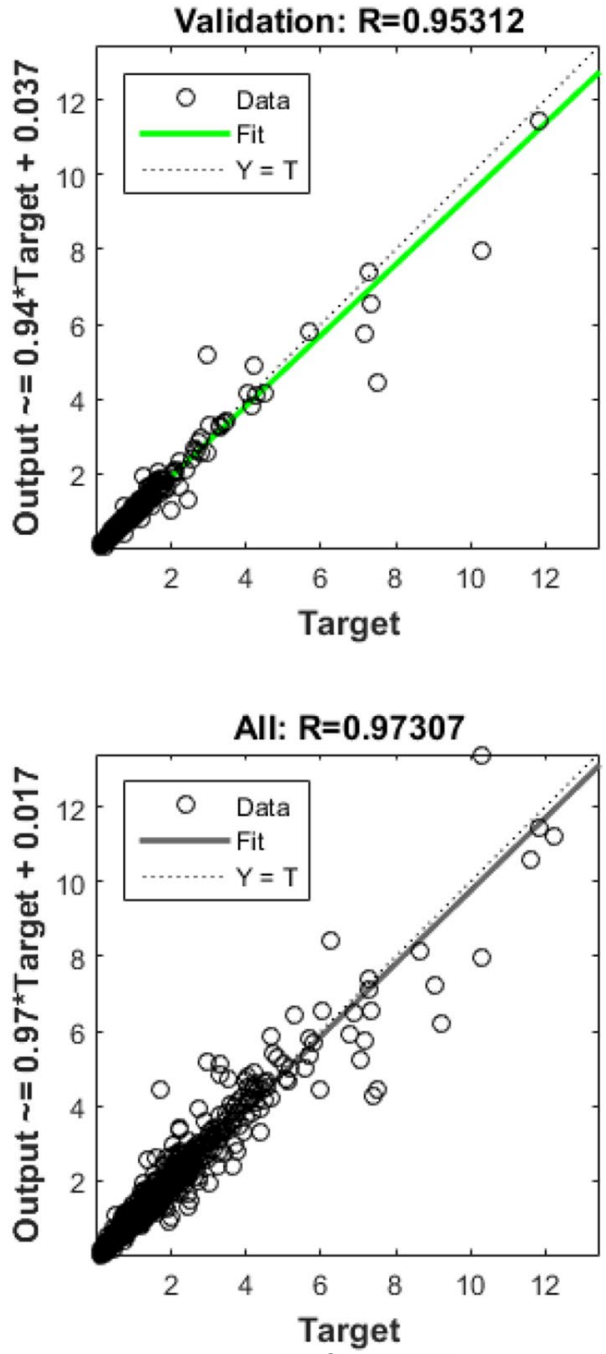

$\sqrt{ }$ 


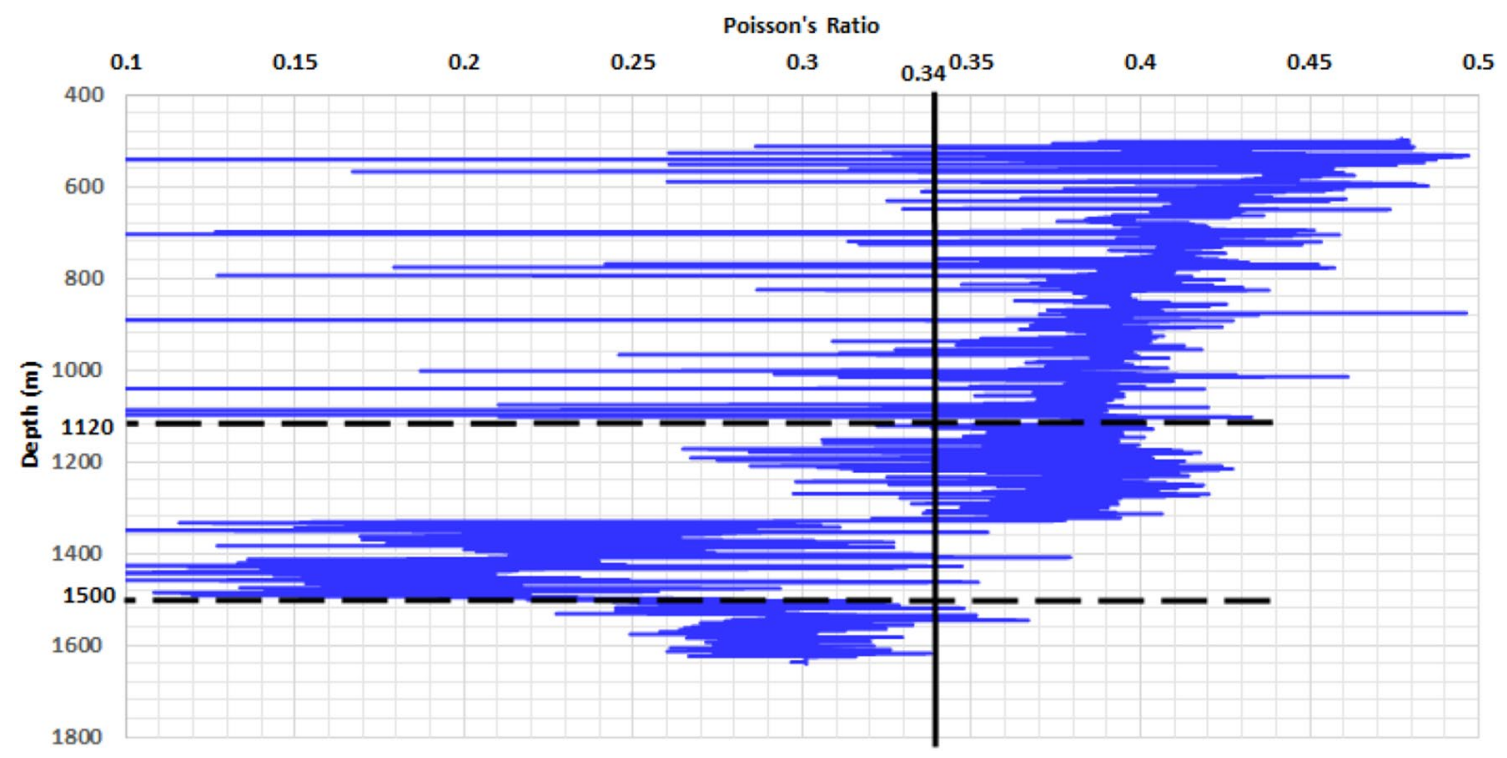

Fig. 16 Poisson's ratio of Field $X$

Table 1 Poisson's ratio for different formations. Source: National Engineering Handbook (2012)

\begin{tabular}{ll}
\hline Poisson's ratio & Formation \\
\hline $0.10-0.30$ & Clay (unsaturated) \\
$0.20-0.30$ & Clay (sandy) \\
$0.40-0.50$ & Clay (saturated) \\
0.15 & Sand (course) \\
0.25 & Sand (fine) \\
$0.20-0.40$ & Sand (dense) \\
$0.30-0.35$ & Silt \\
$0.30-0.40$ & Carbonate \\
$>0.30$ & Shales \\
0.40 & Coal \\
\hline
\end{tabular}

formation compared to the former one. The generated data from well logs were used in MATLAB to validate the correlation between the MPL and the shear modulus with depth. Figure 15 shows that there is a good match with correlation coefficient ' $R$ ' of 0.97 for all data.

\section{Geomechanical model}

In Field $X$, as shown in Fig. 16, the Poisson's ratio (v) varies with the burial depth, ranging from 0.1 to a maximum value of 0.5 . From 1320 to $1500 \mathrm{~m}$, a sudden decrease in ' $v$ ' value from 0.4 to approximately 0.2 was observed. Using the guideline provided in Table 1, there is a high possibility that Field $X$ contains hydrocarbon within this interval. This observation was corroborated with the information from the operator of Field $X$, and it was proven that the particular depth is a hydrocarbon-bearing interval. The threshold for the Poisson's ratio is designated at $v=0.34$. With this criterion, it becomes easier to delineate the interval based on formation strength. Although Poisson's ratio alone is not recommended to distinguish between the hard and soft formation, it serves as a good indicator of the lithology.

A plot of Young's modulus $(E)$ versus depth for Field $X$ is shown in Fig. 17. Ignoring the noises produced during data collection, the graph shows a low value of Young's modulus is observed at depths below $1120 \mathrm{~m}$. Also, it was observed that the transition zone for Field $X$ falls between 1120 and $1500 \mathrm{~m}$. Using the MPL model as a benchmark, the criteria of Young's modulus are set at $1.6 \times 10^{6}$ psi.

Unconfined compressive strength describes the ability of the rock to resist the stress applied. Referring to Table 2 by National Engineering Handbook (2012), the indication of soft sand is formation having low UCS values. UCS was calculated using Bradford et al.'s (1998) correlation, and the results are shown in Fig. 18. Comparing with MPL model, the threshold of UCS is set at 2400 psi.

Figure 19 shows the calculated critical wellbore pressure of Field $X$. The wellbore pressure falls between 1000 psi and 3800 psi. Critical wellbore pressure graph has a similar trend with UCS graph. With the formula of $\Delta P=P_{\mathrm{o}}-P_{\mathrm{c}}$, drawdown pressure can be calculated using overburden pressure minus critical wellbore pressure. As shown in Fig. 19, drawdown pressure has an inverse relationship with critical wellbore pressure at a depth around $1320 \mathrm{~m}$ to $1500 \mathrm{~m}$. Figure 20 shows the predicted results for critical wellbore pressure using MATLAB. The training outcome is satisfying with an average $R$ value of 0.97 . 




Fig. 17 Young's modulus of Field $X$

Table 2 UCS classifications. Source: National Engineering Handbook (2012)

\begin{tabular}{lll}
\hline UCS & & Rock strength \\
\cline { 1 - 2 } MPa & PSI & \\
\hline$<0.60$ & $<87.02$ & Soil \\
$0.60-1.25$ & $87.02-181.30$ & Very soft rock \\
$1.25-5$ & $181.30-725.19$ & Soft rock \\
$5-12.50$ & $725.19-1812.98$ & Moderately soft rock \\
$12.50-50$ & $1812.98-7251.90$ & Moderately hard rock \\
$1-25$ & $145.04-3625.95$ & - \\
$25-50$ & $3625.95-7251.90$ & - \\
$50-100$ & $7251.90-14,503.80$ & Hard rock \\
$100-250$ & $14,503.80-36,259.50$ & Very hard rock \\
$>250$ & $>36,259.50$ & Extremely hard rock \\
\hline
\end{tabular}

The Poisson's ratio of Field $Y$ falls between ranges of 0.30 to 0.45 as shown in Fig. 21. Using MPL model as a guideline, the threshold for Poisson's ratio was set at 0.34, which is same with Field $X$. Infinite slope can be noticed at depth from $1760 \mathrm{~m}$ to $2000 \mathrm{~m}$ and from 2140 to $2440 \mathrm{~m}$. Between 2000 and $2140 \mathrm{~m}$, the Poisson's ratio value was around 0.40 . According to the guideline (Table 1), it was suspected that this zone contains coal mineral. Correlated with lithostratigraphy profile of Field $Y$, this particular zone contains abundant coal layers.

Figure 22 shows a graph of Young's modulus versus depth. With comparison on MPL model, the criterion for Young's modulus is set at $1.6 \times 10^{6} \mathrm{psi}$. Graph shows Young's modulus is increasing with depth, indicating the formation strength is increasing as depth goes down. Above $1760 \mathrm{~m}$, the formation is soft as it is below the adjusted threshold. Starting from 1760 to $2000 \mathrm{~m}$, an infinite slope can be found with the majority of the values below the set threshold. From 2000 to 2140 m, a sudden decrease in Young's modulus indicates the reduction in formation strength. Again, the second transition zone can be found between 2140 and $2440 \mathrm{~m}$. The second transition zone shows the hardest interval in Field $Y$.

Referring to Fig. 23, Field $Y$ shows an average UCS value of 2437.69 psi. Using the guideline provided in Table 2, Field $Y$ shows weak and unconsolidated formation. The shallower formation has lower UCS value. With a set threshold of $2400 \mathrm{psi}$, it was observed that the second transition zone is harder compared to other intervals.

As shown in Fig. 24, critical wellbore pressure of Field $Y$ ranges between 3000 and 7000 psi. From the graph, the increase in critical wellbore pressure is in four sections, from 1266 to $1760 \mathrm{~m}, 1760$ to $2000 \mathrm{~m}, 2000$ to $2140 \mathrm{~m}$ and 2140 to $2400 \mathrm{~m}$. Critical wellbore pressure is important to engineers, especially the operators, as it can indicate the maximum drawdown pressure to operate the well without causing sand failure. By deducting critical wellbore pressure from overburden pressure, drawdown pressure for each interval was plotted. MATLAB result for Field $Y$ critical wellbore pressure is shown in Fig. 25. According to the training outcome, all the $R$ values fall above 0.98 , which shows a good result. 


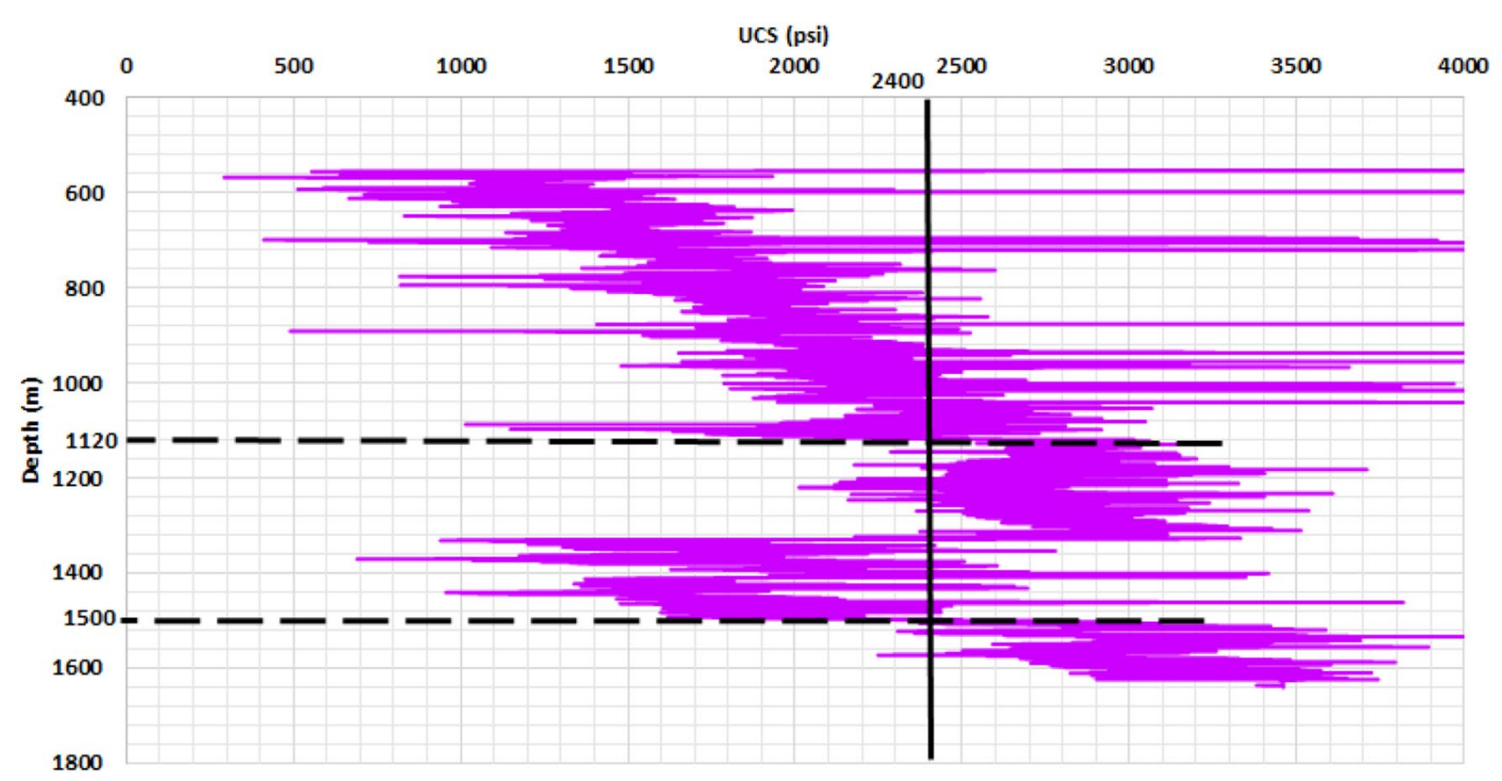

Fig. 18 UCS of Field $X$

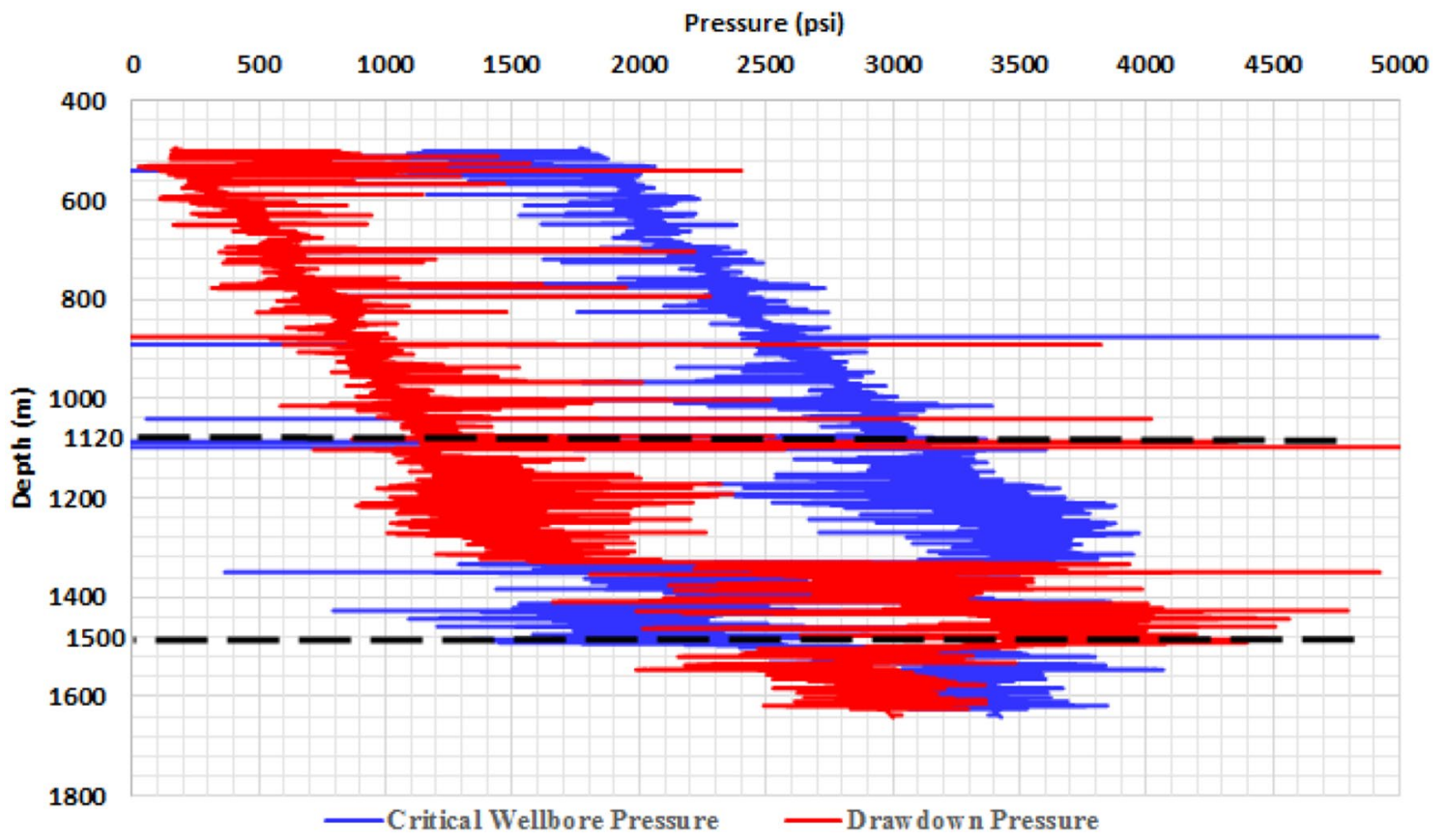

Fig. 19 Critical wellbore pressure and drawdown pressure of Field $X$

\section{Conclusions}

The aim of this study was to investigate the veracity of Tixer et al.'s sanding criteria that are strictly based on the mechanical property log (MPL) and the shear modulus $(G)$. The scope of this study focused on the quick evaluation and qualitative identification of sanding potentials in clean sands using geomechanical properties and well log data. The prediction of critical production rate, sand accumulation in wellbore and screen selection that require the determination of in situ stresses, friction angle, pore pressure and cohesion are not considered. The sanding prediction was conducted using two models: the MPL model and the geomechanical model. Well log data from two fields were used to generate the geomechanical properties and evaluate the reliability of 
Fig. 20 Geomechanical model validation of Field $X$
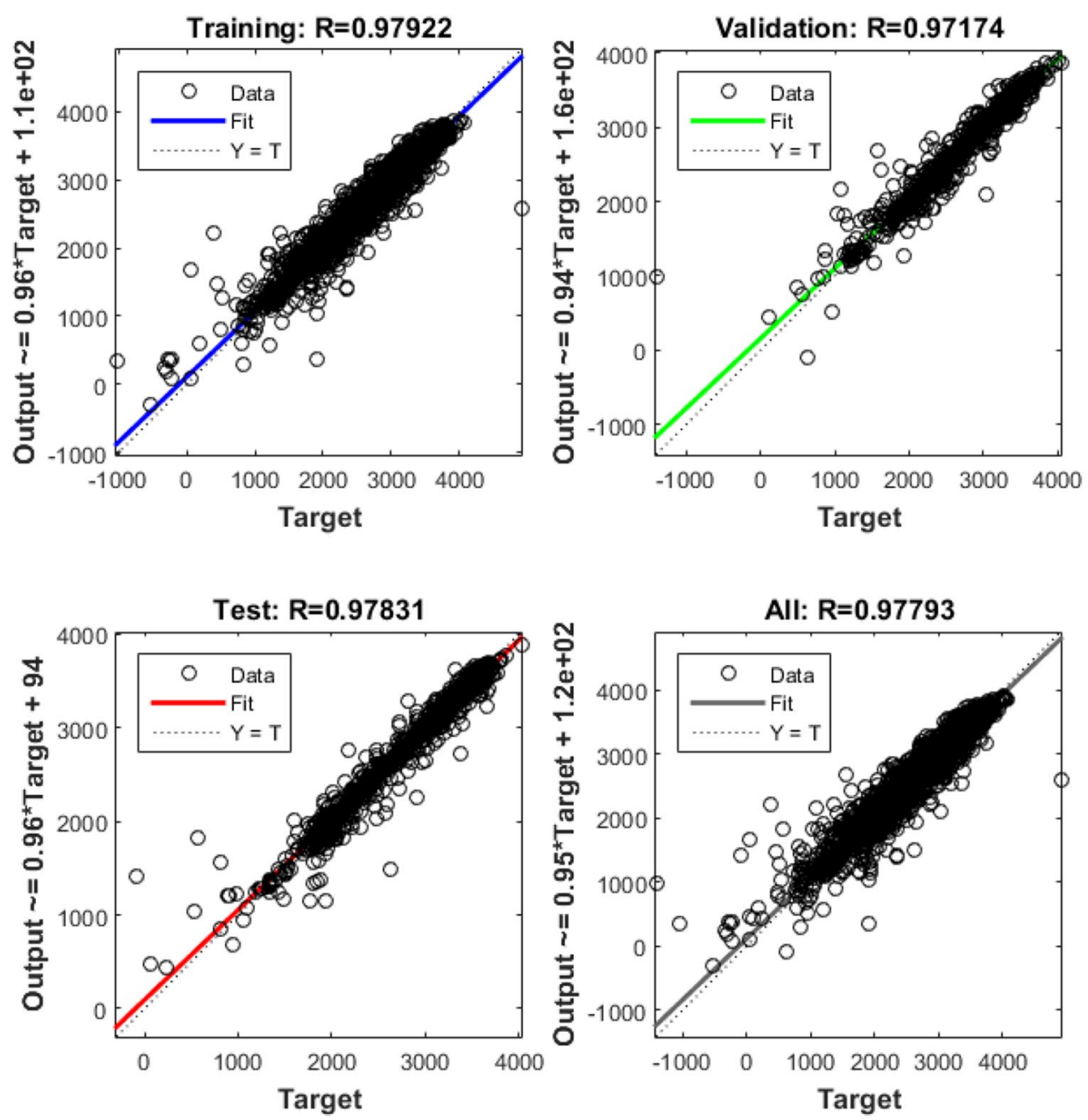

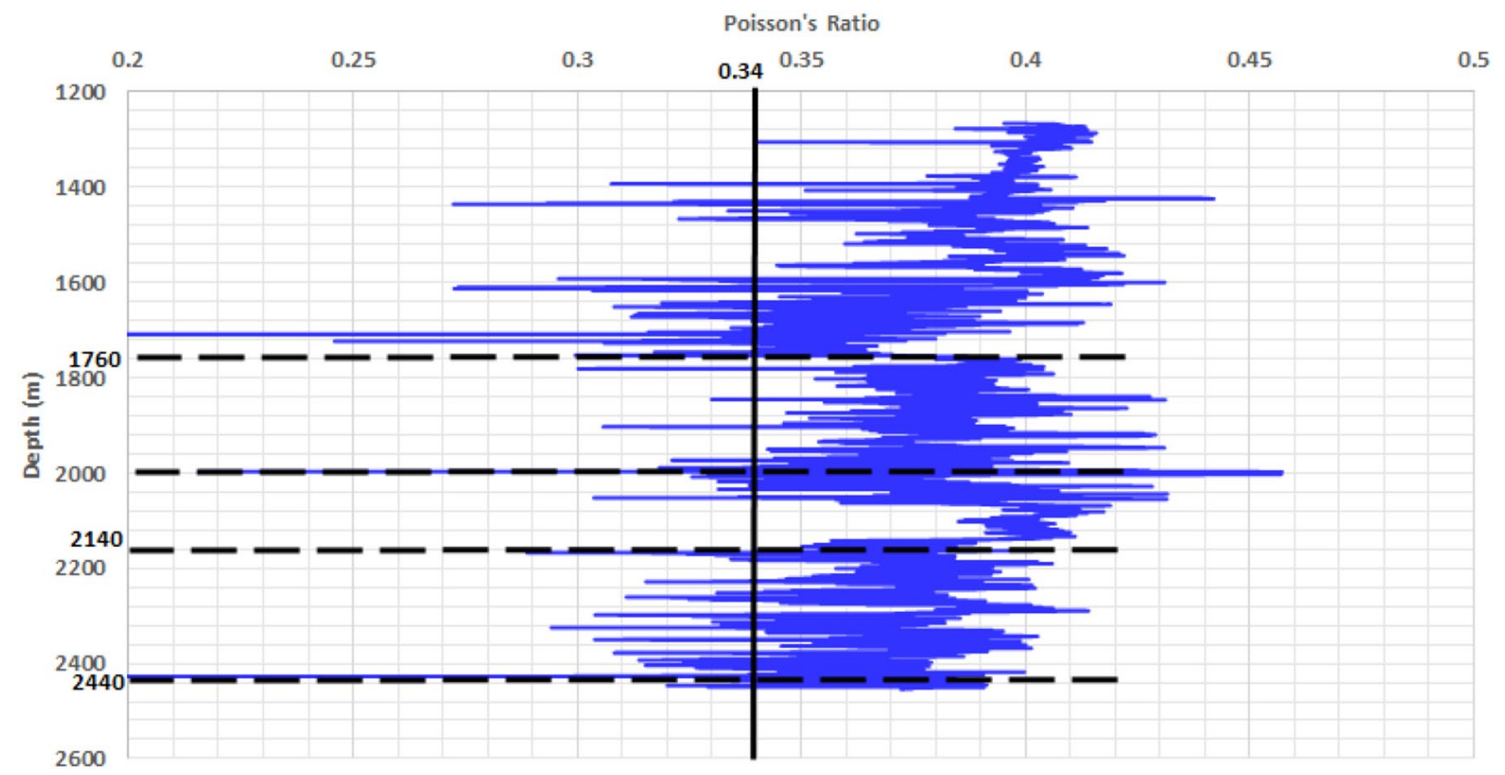

Fig. 21 Poisson's ratio of Field $Y$ 


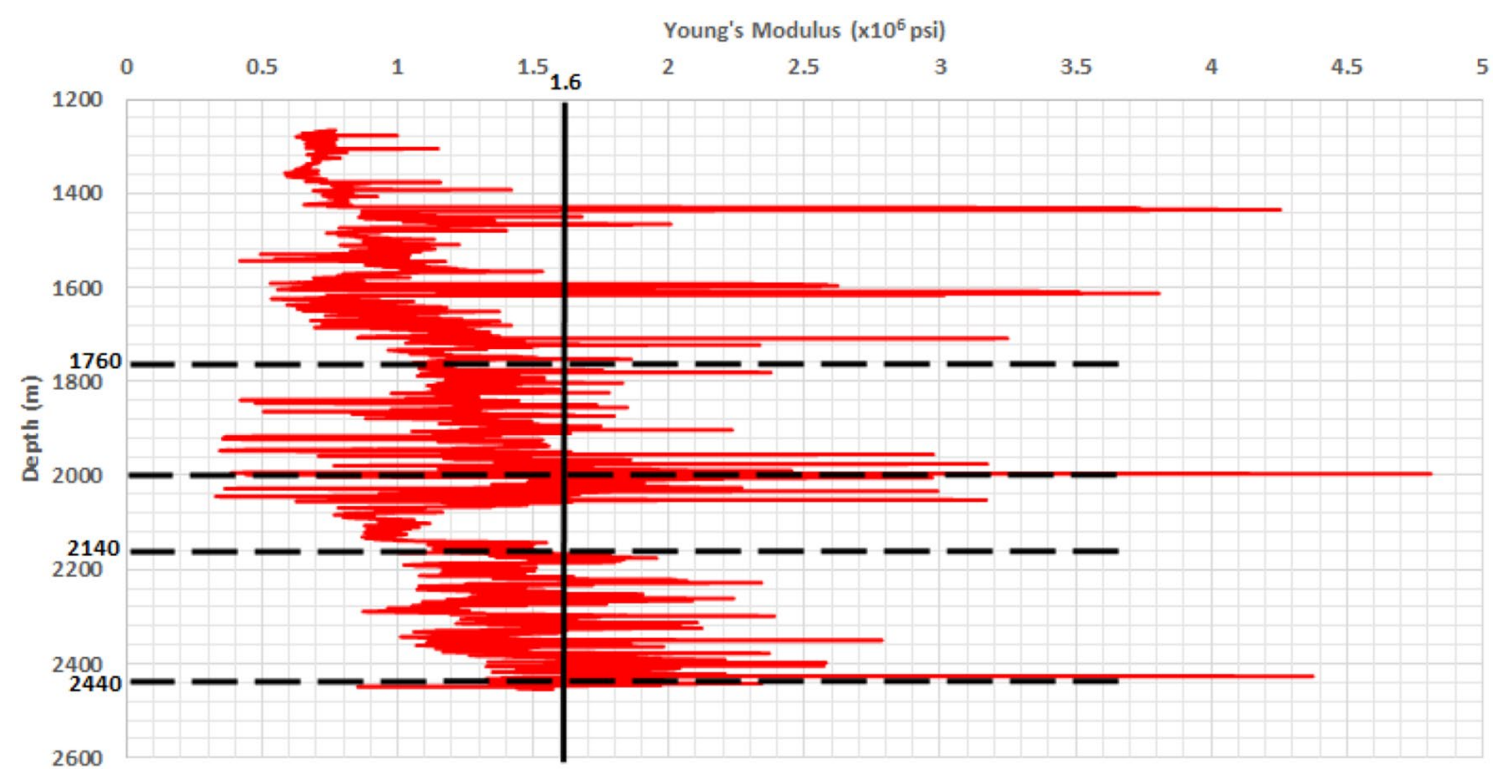

Fig. 22 Young's modulus of Field $Y$

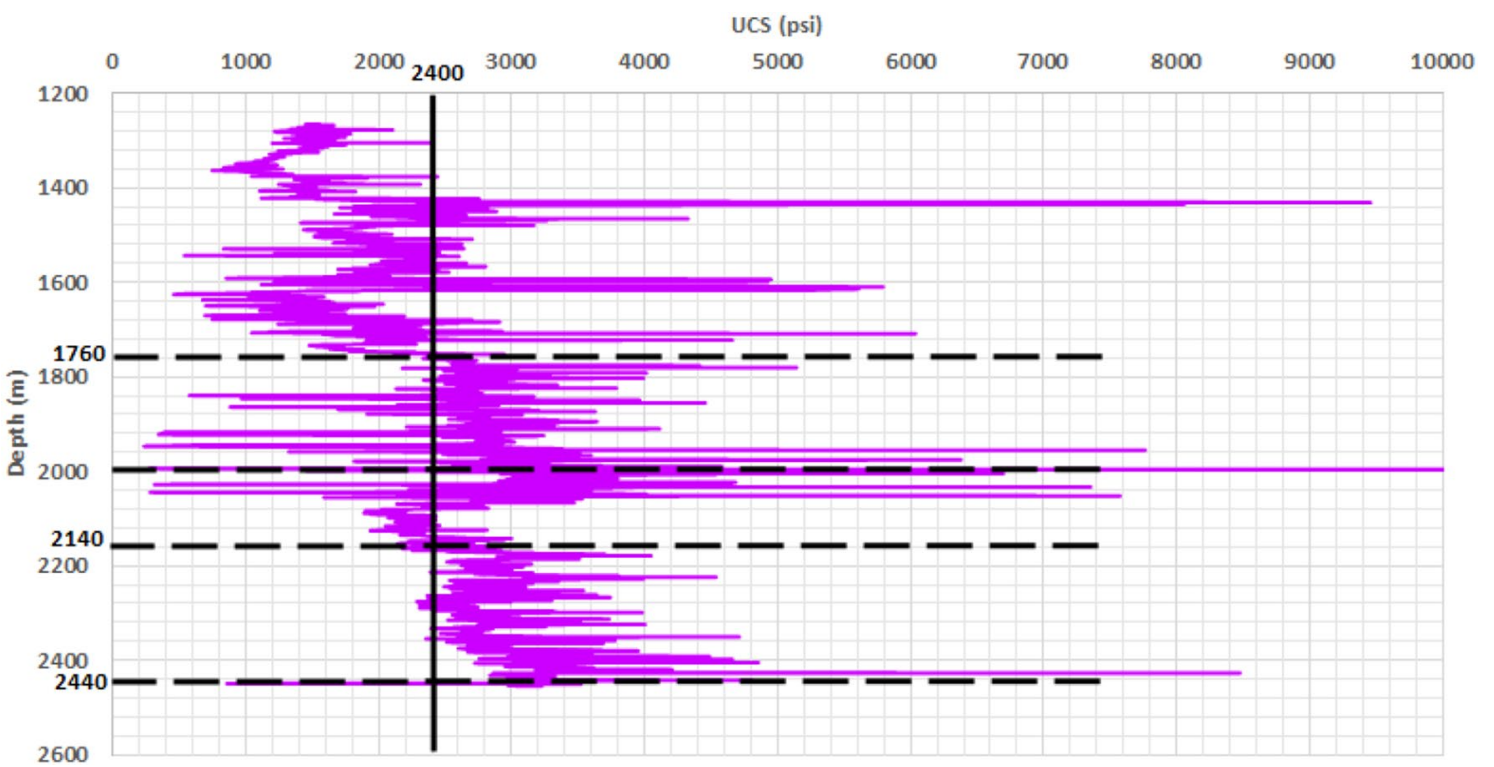

Fig. 23 UCS of Field $Y$

Tixier et al.'s (1975) criteria. The data were subsequently applied to develop new threshold for identifying the transition zone and to differentiate weak or unconsolidated zone from stable or strong zones. Analyses have shown that the Poisson's ratio has a threshold of 0.34 and Young's modulus of $1.6 \times 10^{6}$ psi while the UCS threshold is set at 2400 psi. These values are more consistent than those set by Tixier et al. (1975) to identify failure-prone zones. Values less than the new threshold would indicate potential sand production. This interpretation was validated with excellent results from MATLAB prediction. The application of the geomechanical properties to predict sanding potential in wells has been further established in this work. Transition zone can be identified when the graph shows an infinite slope. This is a 




Fig. 24 Critical wellbore pressure and drawdown pressure of Field $Y$

Fig. 25 Geomechanical model validation of Field $Y$
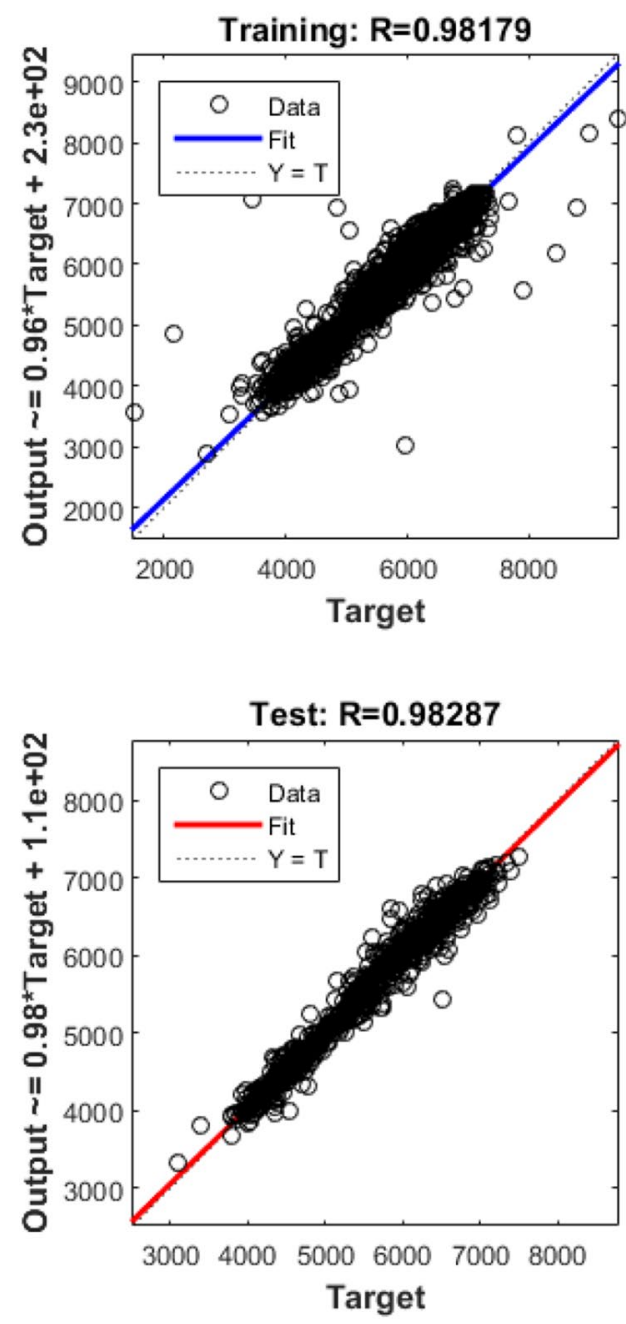
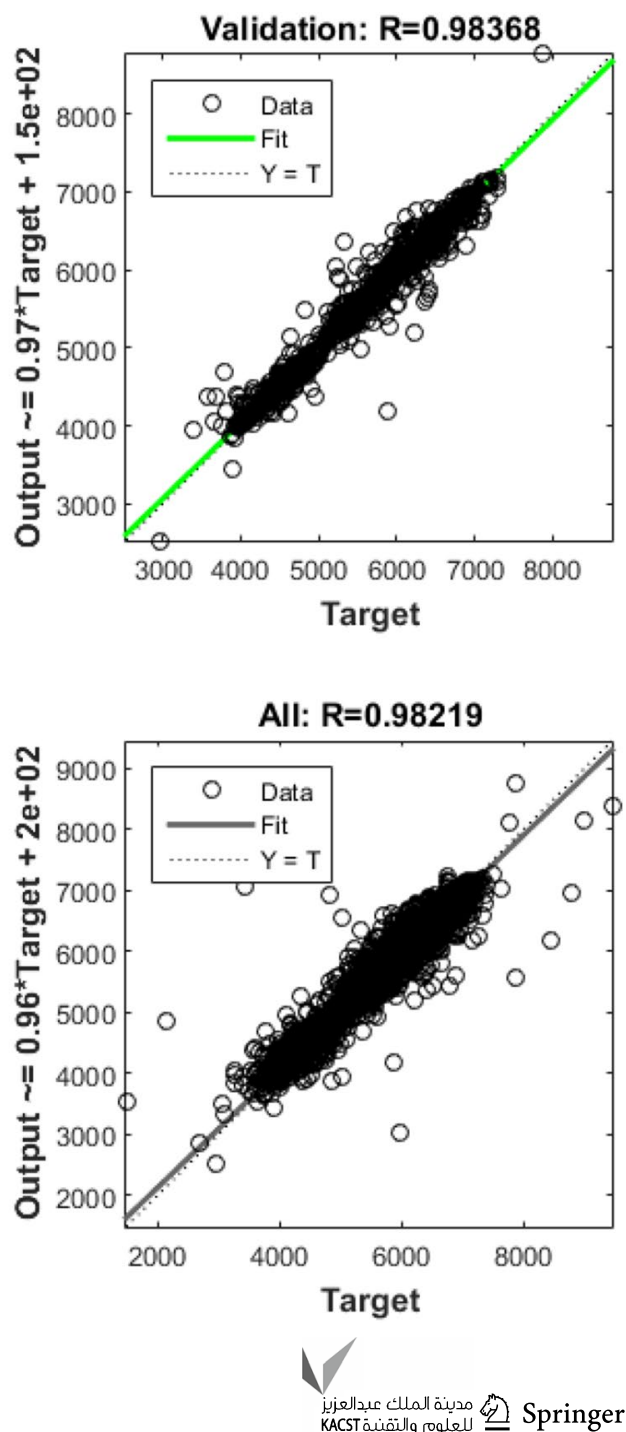
new approach that can be applied to identify the formation strength of the reservoir intervals. The existing MPL model is still applicable but with caution; however, it is recommended that the geomechanical model be used in conjunction with MPL model to obtain more accurate and reliable results.

Acknowledgements The authors thank Universiti Teknologi PETRONAS for the provision of valuable data and the permission to publish this paper.

Open Access This article is distributed under the terms of the Creative Commons Attribution 4.0 International License (http://creativeco mmons.org/licenses/by/4.0/), which permits unrestricted use, distribution, and reproduction in any medium, provided you give appropriate credit to the original author(s) and the source, provide a link to the Creative Commons license, and indicate if changes were made.

\section{References}

Acock A, ORourke T, Shirmboh D, Alexander J, Andersen G, Kaneko T, Venkitaraman A, Lopex-de-Cardenas, Nishi M, Numasawa M, Yoshioka K, Roy A, Wilson A, Twynam A (2004) Practical approaches to sand management. https://pdfs.semanticsc holar.org/8329/9786d7cddfd925112e42ade9f395fff3e033.pdf? $\mathrm{ga}=2.239341574 .447709308 .1569595941-1692135095.15695$ 95941

Aborisade OM (2011): Practical approach to effective sand prediction, control and management. Masters Thesis, African University of science and Technology, Abuja Nigeria. http://repository .aust.edu.ng/xmlui/bitstream/handle/123456789/455/ABORI SADE $\% 2 C O p e y e m i . p d f ?$ sequence $=1 \&$ isAllowed $=y$

Akinsete OO, Ogunkunle TF, Onwuegbu SM, Isehunwa SO (2017) Prediction of sand production in gas and gas condensate wells. J Pet Gas Eng 8(4):29-35

Al-Ajmi AM, Zimmerman RW (2007) The Mogi-Coulomb true-triaxial failure criterion and some implications for rock engineering. In Proceedings of the 11th International Society for Rock Mechanics Congress, pp. 475-486

Al-Awad MN (2012) Evaluation of Mohr-Coulomb failure criterion using unconfined compressive strength. In: ISRM regional symposium-7th Asian rock mechanics symposium

Ameen MS, Smart BG, Somerville JM, Hammilton S, Naji NA (2009) Predicting rock mechanical properties of carbonates from wireline logs (a case study: Arab-D reservoir, Ghawar field, Saudi Arabia). Mar Pet Geol 26:430-444

Araujo Guerrero EF, Alzate GA, Arbelaez-Londono A, Pena S, Cardona A, Naranjo A (2014) Analytical prediction model of sand production integrating geomechanics for open hole and casedperforated wells. In: SPE heavy and extra heavy oil conference: Latin America

Balarabe T, Isehunwa S (2017) Evaluation of sand production potential using well logs. Soc Petrol Eng. https://doi.org/10.2118/18910 7-MS

Bradford I, Fuller J, Thompson P, Walsgrove T (1998) Benefits of assessing the solids production risk in a North Sea reservoir using elastoplastic modelling. In: SPE/ISRM rock mechanics in petroleum engineering

Cui Y, Wang G, Jones SJ, Zhou Z, Ran Y, Lai J (2017) Prediction of diagenetic facies using well $\log s$ - a case study from the upper Triassic Yanchang formation, Ordos Basin, China. Mar Pet Geol 81:50-65
Deng F, Deng J, Yan W, Zhu H, Huang L, Chen Z (2013) The influence of fine particles composition on optimal design of sand control in offshore oilfield. J Pet Explor Prod Technol 3:111. https://doi.org/10.1007/s13202-012-0045-7

Dong M, Long B, Lun L, Juncheng H (2013) Application of logging data in predicting sand production in oilfield. Electron J Geotech Eng 18:6173-6180

Elkatatny S, Zeeshan T, Mahmoud M, Abdulazeez A, Mohamed I (2016) Application of artificial intelligent techniques to determine sonic time from well logs. In: 50th US rock mechanics/ geomechanics symposium

Eyinla DS, Oladunjoye MA (2014) Estimating geo-mechanical strength of reservoir rocks from well logs for safety limits in sand-free production. J Environ Earth Sci 4:38-43

Freyburg E (1972) Der Untere und mittlere Buntsandstein SWThuringen in seinen gesteinstechnicschen Eigenschaften. Deustche Gesellschaft Geologische Wissenschaften 176:911-919

Fulong N, Nengyou W, Shi L, Zhang K, Yibing Y, Li L (2013) Estimation of in situ mechanical properties of gas hydrate-bearing sediments from well logging. Pet Explor Dev 40:542-547

Galindo R, Serrano A, Olalla C (2017) Ultimate bearing capacity of rock masses based on modified Mohr-Coulomb strength criterion. Int J Rock Mech Min Sci 93:215-225

Gatens JM, Harrison CW, Lancaster DE, Guidry FK (1990) In-situ stress tests and acoustic logs determine mechanical properties and stress profiles in the Devonian shales. Soc Pet Eng. https:// doi.org/10.2118/18523-pa

Guinot F, Douglass S, Duncan J et al (2009) Sand exclusion and management in the okwori subsea oil field, Nigeria. SPE Drilling Completion 24(1):157-168

Hayavi MT, Abdideh M (2016) Establishment of tensile failure induced sanding onset prediction models for cased-perforated gas wells. J Rock Mech Geotech Eng 9:260-266

Holtz RD, Kovacs WD (1981) An introduction to geotechnical engineering, 2nd edn. Prentice Hall, New Jersey, p 508

Horsrud P (2001) Estimating mechanical properties of shale from empirical correlations. SPE Drill Complet 16:68-73

Howarth D (1984) Apparatus to determine static and dynamic elastic moduli. Rock Mech Rock Eng 17:255-264

Hsieh B, Chilingar G, Lu M, Lin ZS (2007) Estimation of groundwater aquifer formation-strength parameters from geophysical well logs: the southwestern coastal area of Yun-Lin, Taiwan. Energy Sources Part A 29:97-115

Hsieh BZ, Wang CW, Lin ZS (2009) Estimation of formation strength index of aquifer from neural networks. Comput Geosci 35:1933-1939

Ispas I, Bray RA, Palmer ID, Higgs NG (2002) Prediction and evaluation of sanding and casing deformation in a GOM shelf well. In: Proceedings of the SPE/ISRM rock mechanics conference, Irving, Texas, 20-23 October

Karacan CO (2009) Elastic and shear moduli of coal measure rocks derived from basic well logs using fractal statistics and radial basis functions. Int J Rock Mech Min Sci 46:1281-1295

Khair EMM, Zhang S, Abdelrahman IM (2015) Correlation of rock mechanic properties with wireline log porosities through fulla oilfield - mugllad basin -sudan. Soc Petrol Eng. https://doi. org/10.2118/175823-MS

Khamehchi E, Reisi E (2015) Sand production prediction using ratio of shear modulus to bulk compressibility (case study). Egypt J Pet 24:113-118

Khamehchi E, Kivi IR, Akbari M (2014) A novel approach to sand production prediction using artificial intelligence. J Petrol Sci Eng 123:147-154

Kowalski J (1975) Formation strength parameters from well logs. Society of Petrophysicists and Well-Log Analysts 
Kolawole O, Federer-Kovács G, Szabó I (2018) Formation susceptibility to wellbore instability and sand production in the Pannonian Basin, Hungary. In: Proceedings of 52nd U.S. rock mechanics/ geomechanics symposium. American Rock Mechanics Association, ARMA-2018-221

Labuz JF, Zang A (2012) Mohr-Coulomb Failure Criterion. Rock Mech Rock Eng 45:975. https://doi.org/10.1007/s00603-012-0281-7

Lacy LL (1997) Dynamic rock mechanics testing for optimized fracture designs. In: SPE annual technical conference and exhibition

Miller SLM, Stewart RR (1991) The relationship between elastic-wave velocities and density in sedimentary rocks: a proposal. https:// www.crewes.org/ForOurSponsors/ResearchReports/1991/199117.pdf. Retrieved 5 August 2019

Mirzaahamdain Y (2011) Application of petrophysical logs and failure model for prediction of sand production. University of Stavanger, Stavanger

Mohamad-Hussein A, Ni Q (2018) Numerical modeling of onset and rate of sand production in perforated wells. J Pet Explor Prod Technol 8:1255. https://doi.org/10.1007/s13202-018-0443-6

Osisanya SO (2010) Practical guidelines for predicting sand production. In: SPE 136980 presented at the 34th SPE annual International conference and exhibition, Tinapa, Nigeria, 31st July-7th August

Onyia EC (1988) Relationships between formation strength, drilling strength, and electric log properties. Soc Petrol Eng. https://doi. org/10.2118/18166-MS

Oyeneyin B (2015) Chapter 4: Fundamentals of petrophysics and geomechanical aspects of sand production forecast. Dev Pet Sci 63:139-171. https://doi.org/10.1016/B978-0-444-62637-0.00004 $-\mathrm{X}$

Palmer I, Vaziri H, Willson S, Moschovidis Z, Cameron J, Ispas I (2003) Predicting and managing sand production: a new strategy. Soc Petrol Eng. https://doi.org/10.2118/84499-MS

Qi L, Carr TR (2006) Neural network prediction of carbonate lithofacies from well logs, Big Bow and Sand Arroyo Creek fields, Southwest Kansas. Comput Geosci 32:947-964

Rahmati H, Jafarpour M, Azadbakht S, Nouri A, Vaziri H, Chan D (2013) Review of sand production prediction models. J Pet Eng 2013:1

Rajabi M, Bohloli B, Ahangar EG (2010) Intelligent approaches for prediction of compressional, shear and Stoneley wave velocities from conventional well log data: a case study from the Sarvak carbonate reservoir in the Abadan Plain (Southwestern Iran). Comput Geosci 36:647-664

Ranjith PG, Perera MSA, Perera WKG, Wu B, Choi SK (2013) Effective parameters for sand production in unconsolidated formations: an experimental study. J Petrol Sci Eng 105:34-42
Sethi DK (1981) Well log applications in rock mechanics. Soc Petrol Eng. https://doi.org/10.2118/9833-MS

Subbiah SK, de Groot L, Graven H (2014) An innovative approach for sand management with downhole validation. In: Proceedings of the SPE international symposium and exhibition on formation damage control, Lafayette, Louisiana, 26-28 February

Tan M, Peng X, Cao H, Wang S, Yuan Y (2015) Estimation of shear wave velocity from wireline logs in gas-bearing shale. J Pet Sci Eng 133:352-366

Tixier M, Loveless G, Anderson R (1975) Estimation of Formation Strength From the Mechanical-Properties Log (incudes associated paper 6400). J Pet Technol 27:283-293

USDA NRCS (2012) Engineering classification of rock materials Chapter 4, Part 631 Geology national engineering handbook, 210-VI-NEH, Amend. 55. https://directives.sc.egov.usda.gov/ OpenNonWebContent.aspx? content $=31848$. wba. Retrieved 25 April 2017

Wang X (2017) Technology focus: sand management and sand control. SPE-1017-0098-JPT J Pet Technol 69:10. https://doi. org/10.2118/1017-0098-JPT

Wang Y, Ge S, Guo G (2004) Mining science and technology. In: Proceedings of the 5 th international symposium on mining science and technology, Xuzhou, China 20-22 October 2004: CRC Press, 2004

Willson SM, Moschovidis ZA, Cameron JR, Palmer ID (2002) New model for predicting the rate of sand production. In: Proceedings of the SPE/ISRM rock mechanics conference, Irving, Texas, 20-23 October

Yale DP, Jamieson WH (1994) Static and dynamic mechanical properties of carbonates. American Rock Mechanics Association

Zhaoping M, Suping P, Jitong F (2002) Study on control factors of rock mechanics properties of coal-bearing formation. Chin J Rock Mech Eng 21:103-105

Zhou S, Sun F (2016) Sand production management for unconsolidated sandstone reservoirs, 1st edn. Wiley, Singapore, pp 12-33

Publisher's Note Springer Nature remains neutral with regard to jurisdictional claims in published maps and institutional affiliations. 